\title{
Analyzing Tight Sand Characteristics and Its Influence on Aqueous Phase Removal by Gas Displacement
}

\author{
Mianmo Meng $\mathbb{D},{ }^{1}$ Hongkui Ge $\mathbb{D}^{1,2}$ Yinghao Shen $\mathbb{D}^{1},{ }^{1}$ Wenming Ji, ${ }^{3}$ Yang Wu, \\ Xiaosong Xu, ${ }^{1}$ Weihan Huang, ${ }^{1}$ Qinyu $\mathrm{Li}^{1}{ }^{1}$ and Jiayao $\mathrm{Yu}^{1}$ \\ ${ }^{1}$ State Key Laboratory of Petroleum Resources and Prospecting, China University of Petroleum, Beijing 102249, China \\ ${ }^{2}$ China University of Petroleum-Beijing at Karamay, Karamay 834000, China \\ ${ }^{3}$ School of Geoscience, China University of Petroleum, Qingdao 266580, China
}

Correspondence should be addressed to Mianmo Meng; mmmcup@163.com and Yinghao Shen; shenyinghao@126.com

Received 25 November 2018; Accepted 3 March 2019; Published 23 April 2019

Academic Editor: Andrea Brogi

Copyright ( 2019 Mianmo Meng et al. This is an open access article distributed under the Creative Commons Attribution License, which permits unrestricted use, distribution, and reproduction in any medium, provided the original work is properly cited.

\begin{abstract}
Tight sand gas is an important unconventional natural gas. Liquid filtration plays a main role in the formation damage. Flowback rate is closely related to the formation permeability recovery. Usually, the more flowback rate is, the better the permeability recovery is. In order to research the factors that influence the liquid flowback, the tight sand characteristics and gas displacement have been investigated. Some experiments were carried out, including porosity, permeability, XRD, casting thin section, SEM, stress sensitivity, rock expansion, and gas displacement. The results are shown as follows. Taiyuan formation has average high clay content than $\mathrm{H} 8$ formation. Illite is the main clay in Taiyuan formation; chlorite is the main clay in $\mathrm{H} 8$ formation. From the casting thin section, the rock has strong compression. Taiyuan formation has large pore. However, H8 formation mainly has small cracks. Through the SEM, there are many micro- to nanocracks as well as some pores in these two formations. In some cases, cracks penetrate the clays. From the permeability stress sensitivity, these tight sands have strong stress sensitivity. Permeability decreases quickly with increasing confining pressure. In the rock expansion experiment, the tight sand has less expansion rate compared with shale gas rock and volcanic gas rock. Rock expansion rate has positive relationship with clay content. In the gas displacement experiment, usually the higher the clay content, the lesser the liquid flowback. Some samples have high clay content. However, it has high flowback rate, which may account for good pore connection. Through the above study, the flowback rate has negative relationship with clay content and positive relationship with pore size, pore connection, and displacement pressure. In order to increase tight gas production in the study area, the formation should have high flowback rate and less liquid retention. Therefore, clay expansion preventing additives should be added into the fracturing liquid to reduce the liquid retention. The quick flowback should be implemented after hydraulic fracturing for reducing the interaction between liquid and rock. At the same time, the drawdown pressure should keep in a certain value to reduce stress sensitivity.
\end{abstract}

\section{Introduction}

With increasing energy requirement, unconventional natural gas attracts our attention [1-9]. Tight sand reservoirs belong to unconventional reservoirs and have low porosity and permeability [10-13]. Ordos basin has abundance of tight gas, such as in the Sulige area. Ordos basin is the second largest hydrocarbon-bearing onshore basin in China with an area of about $250000 \mathrm{~km}^{2}$ [14]. Lots of work has been carried out to learn tight reservoir and to effectively develop it. The basic characteristic investigation is firstly necessary, such as the mineral components and pore characteristics. In order to characterize the property of tight sand, many microscopic experiments have been carried out by previous research, such as casting thin section, scanning electronic microscope (SEM), and CT scanning [15-18]. Despite the microstructure investigation, the gas flowing in the microto nanopore is closely related to the production, which can be reflected through permeability.

Tight sand initial permeability which is usually less than $1 \mathrm{mD}[19-22]$ has been widely researched [23, 24], especially the permeability stress sensitivity [25-28]. Different methods 


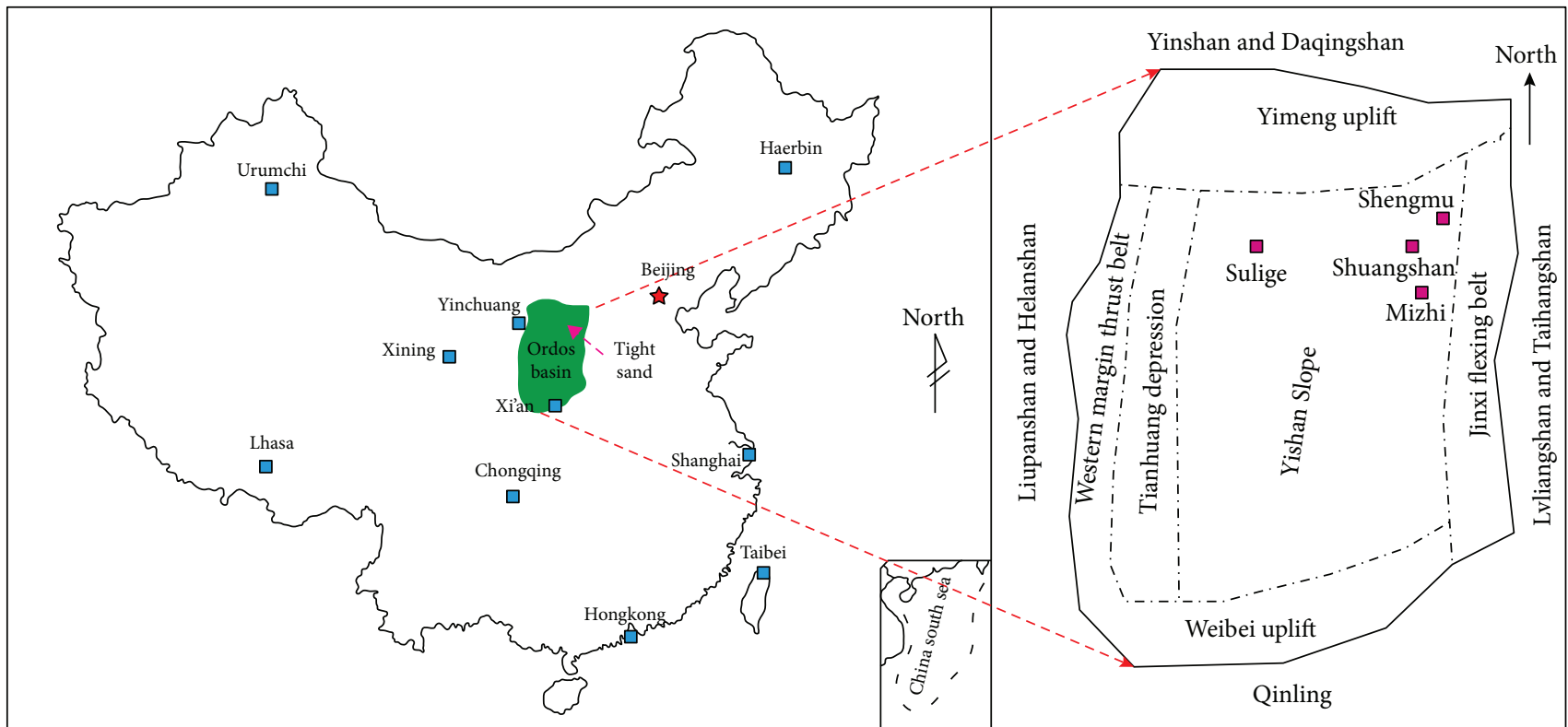

(a)

(b)

Figure 1: The simple map of the study area. (a) China map; (b) the amplification map of the green part in (a).

have been used to measure tight sand permeability, mainly including traditional steady-flow permeability measurement and pulse-decay permeability measurement [29-33]. Traditional permeability measurement method was carried out by monitoring the fluid flowing rate passing through the sample. Under similar condition, the high-permeable sample has higher flowing rate than the one of low-permeable sample. Pulse-decay permeability measurement is according to monitoring the pulse-decay rate between two ends of sample. The quicker the deferential pressure decay, the higher the tested sample permeability. The permeability under different water saturation has been investigated $[34,35]$. Tight sand permeability can be estimated by other ways, such as mercury injection capillary pressure (MICP) and nuclear magnetic resonance (NMR) [36]. Many models have been provided to calculate the permeability through MICP experiment [37-40]. Low-field NMR has also been widely used to appraise the rock permeability [41, 42].

Due to the low permeability of tight sand reservoirs, the initial production is very low. The hydraulic fracturing method becomes a significant method to stimulate this kind of tight formation for realizing commercial production [43-47]. However, large amount of liquid retain in the formation after flowback $[13,48]$. Thus, the reservoir permeability was damaged severely, which reduce the effective gas flowing during production [49-54]. The same water saturation in tight gas reservoir has more impact on permeability than conventional gas reservoir [55]. Permeability jail exists in tight reservoir. Permeability jail is that an interval has no gas and liquid permeability. Thus, decreasing the aqueous phase saturation is very important in tight reservoir. The removal of aqueous phase trapping has been researched by previous experts [56-58]. It shows that pressure drawdown higher than the threshold capillary pressure can remove aqueous phase trapping. Permeability recovery is very important during flowback after hydraulic fracturing. Displacement experiment plays a significant role in appraising the liquid flowback rate and permeability recovery rate $[59,60]$. Some researchers show that displacement plays more important role in a short period, and evaporation has great impact in the long period for aqueous phase removal in reservoirs $[61,62]$. In order to better understand the displacement process, the liquid filling process should be paid attention. Pendular ring has more impact on gas flowing than the liquid filling, because liquid filling usually fill the smallest pores. Pendular ring can block the throat [63]. In the process of displacement, the smallest pores are unlikely displaced due to its high capillary force, which also has less contribution to the permeability. Enough gas drawdown pressure is necessary to penetrate the pendular ring for forming gas flowing.

In our paper, the tight sand characteristics have been investigated firstly and then its influence on the liquid flowback and permeability recovery. This research contributes to better understand the study area basic property and its influence on the flowback efficiency.

\section{Samples and Experimental Methods}

2.1. Samples. Tight sandstone samples were taken from the Upper Paleozoic Taiyuan and H8 formation in the Ordos basin of China. The simple map of research place was shown in Figure 1. The green part in Figure 1(a) is the study area, which is magnified as shown on the right picture. The H8 and Taiyuan formations are the main plays for tight gas production in Ordos basin. $\mathrm{H} 8$ formation in Sulige has been studied comprehensively. However, the eastern Ordos basin tight sand has been less researched. The eastern Ordos basin is full of tight gas. The effective development of natural gas in 
TABLE 1: Main experimental samples.

\begin{tabular}{|c|c|c|c|c|c|c|c|c|c|}
\hline \multirow{2}{*}{ Taiyuan formation } & Shenmu & S20-1 & S20-3 & S20-4 & S20-6 & S30-2 & $\mathrm{S} 30-3$ & & \\
\hline & Shuangshan & S96-1 & S96-3 & S96-5 & S120-1 & S120-2 & S120-4 & S126-2 & S127-6 \\
\hline \multirow{3}{*}{ H8 Formation } & Mizhi & M47-2 & M47-3 & M47-5 & M72-3 & M72-4 & & & \\
\hline & Shuangshan & S108-5 & S123-1 & S123-3 & S124-2 & S133-4 & & & \\
\hline & Sulige & S15-1 & S15-6 & S25-4 & S31-1 & S31-2 & & & \\
\hline
\end{tabular}

this area is very important to greatly increase the natural gas production [14].

The main experimental samples are presented in Table 1. The samples are from the Shenmu, Shuangshan, Mizhi, and Sulige area in Ordos basin. There are 6 samples from Taiyuan formation in the Shenmu area. There are 13 samples from the Shuangshan area, including 8 Taiyuan formation samples and $5 \mathrm{H} 8$ formation samples. There are 5 samples from $\mathrm{H} 8$ formation in the Mizhi area. There are 5 samples from $\mathrm{H} 8$ formation in the Sulige area.

2.2. Experimental Methods. Experiments have been carried out to investigate the tight sand characteristics and its influence on the displacement behavior, including XRD mineral analysis, casting thin section, scanning electronic microscope, stress sensitivity, clay expansion, and nitrogen displacement. The detailed experimental methods were shown as follows.

Porosity and initial permeability has been measured before other experiments. Porosity was measured without confining pressure, and the pore pressure is about $0.8 \mathrm{MPa}$. Initial permeability was measured under confining pressure with $5 \mathrm{MPa}$ and pore pressure with $0.25 \mathrm{MPa}$. The testing gas used in porosity measurement was helium. The testing gas used in permeability measurement was nitrogen.

XRD mineral analysis was used to calculate different mineral composition, such as quartz content, feldspar content, and clay content. Different kinds of clay content can be measured through this experiment.

Casting thin section can be used to differentiate the different mineral particles and pore and crack characteristics. Plane-polarized light can reflect the pore distribution. The connected pores were filled with blue material, so that it can be seen through optical microscope. Perpendicularpolarized light can reflect the mineral distribution, especially the particle-contacting characteristics.

Scanning electronic microscope (SEM) was used to reflect the pore and mineral characteristics. It can show much better picture than casting thin section, especially the clay microscope characteristics and small pores.

Permeability stress sensitivity was used to appraise the permeability change with confining stress. The permeability decreases during loading process and increases in the process of unloading. It is closely related to crack closure and pore compression, which is very important during oil/gas development. The pore pressure keeps $0.25 \mathrm{MPa}$. The confining pressure changes from $5 \mathrm{MPa}$ to $25 \mathrm{MPa}$ and then unloading from $25 \mathrm{MPa}$ to $5 \mathrm{MPa}$. It can reflect the pressure loading loss and permeability recovery rate after unloading. The testing gas is nitrogen.
Sample expansion experiment was used to research the clay expansion characteristics during liquid filtration. Clay expansion usually damage the formation permeability. The sample preparation was shown as follows. Firstly, the sample was ground into 200 400 mesh number, whose diameter is about $38 \sim 75 \mu \mathrm{m}$. Taking $10 \mathrm{~g}$ particles for experiment, compress it under axial pressure with $15 \mathrm{MPa}$ for $15 \mathrm{~min}$ and then make it into column shape. During experiment, put the sample into the chamber and make liquid contact to the sample and then measure the expansion distance with time. Expansion rate is ratio between expansion distance and initial sample length. Testing liquid is distilled water.

Nitrogen displacement was carried out to investigate the permeability change with liquid saturation. The permeability increases with displacement time and with high displacement pressure. The samples are column shape. The samples were dried in the oven for 24 hours under $105^{\circ} \mathrm{C}$ before testing. The initial saturation was established by imposing the sample with fluid pressure of $25 \mathrm{MPa}$ for 48 hours after the sample was vacuumized. The liquid was distilled water.

\section{Results}

3.1. Initial Porosity and Permeability. The porosity and permeability of samples were shown in Figure 2. Before experiment, the rocks were processed into cylindrical samples. The number of total experimental samples is 93 . There are 36 and 57 for Taiyuan and H8 formations, respectively. In Figure 2(a), most porosity distributes among 5-10\% of both Taiyuan and $\mathrm{H} 8$ formations, which is more than half of the total samples. The porosity of samples with $15-20 \%$ is less. It indicates that most samples remain low porosity. Simultaneously, the porosity of Taiyuan formation is no larger than 15\%. In Figure 2(b), samples with 0.1-0.5 mD exceed half of the experiment samples. Permeability under $0.1 \mathrm{mD}$ in Taiyuan formation is larger than that in $\mathrm{H} 8$ formation. It shows more low-permeability rocks in Taiyuan formation. There are less percent with permeability larger than $1 \mathrm{mD}$ in Taiyuan formation and H8 formation. Through the analysis of porosity and permeability, it shows that low porosity and permeability is the characteristics of this area.

3.2. Minerals Component Analysis. From Figure 3, the quartz content in all samples is very high. Some samples even reach $91.2 \%$ and $91.6 \%$ in $\mathrm{H} 8$ formation, which is typical quartz sandstone. Most of the samples are lithic quartz sandstone, including all Taiyuan formation. The feldspar content is very small and can be neglected.

In Figure 4, the average total clay content $(24.35 \%)$ in Taiyuan formation is larger than the average total clay 


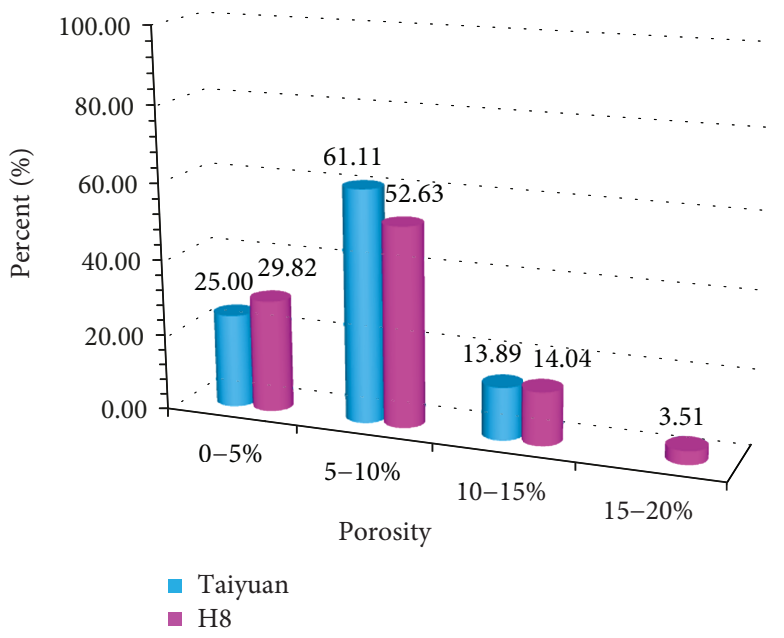

(a)

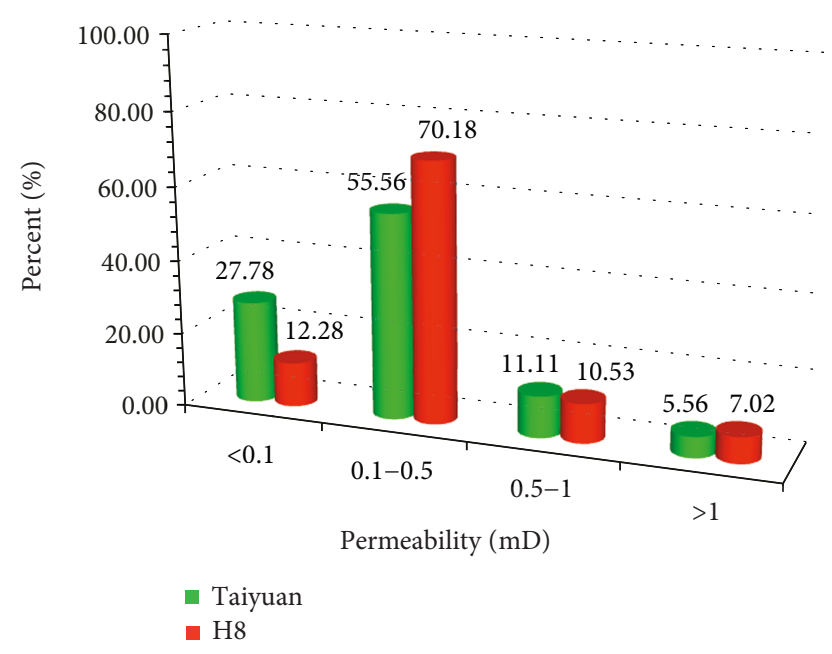

(b)

Figure 2: The distribution of porosity (a) and permeability (b) of samples.

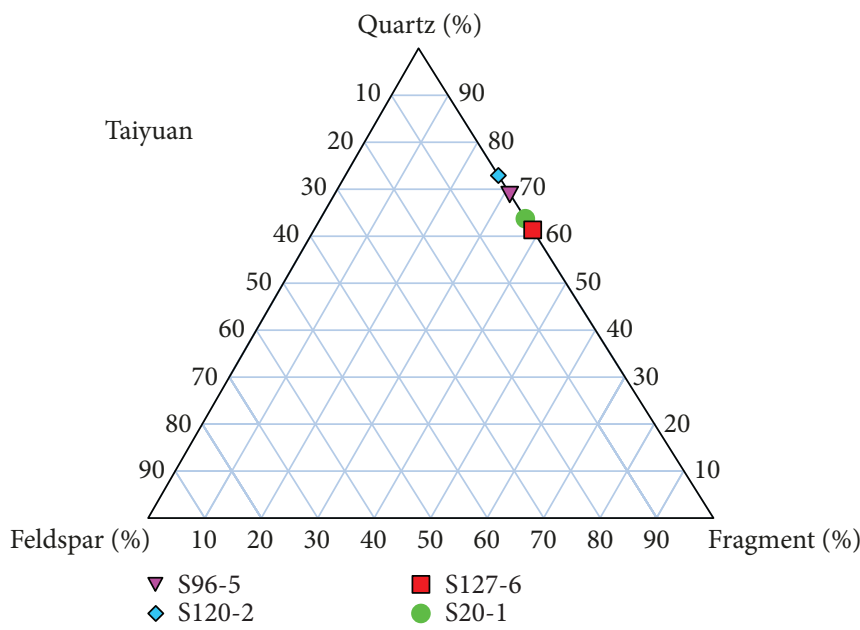

(a)

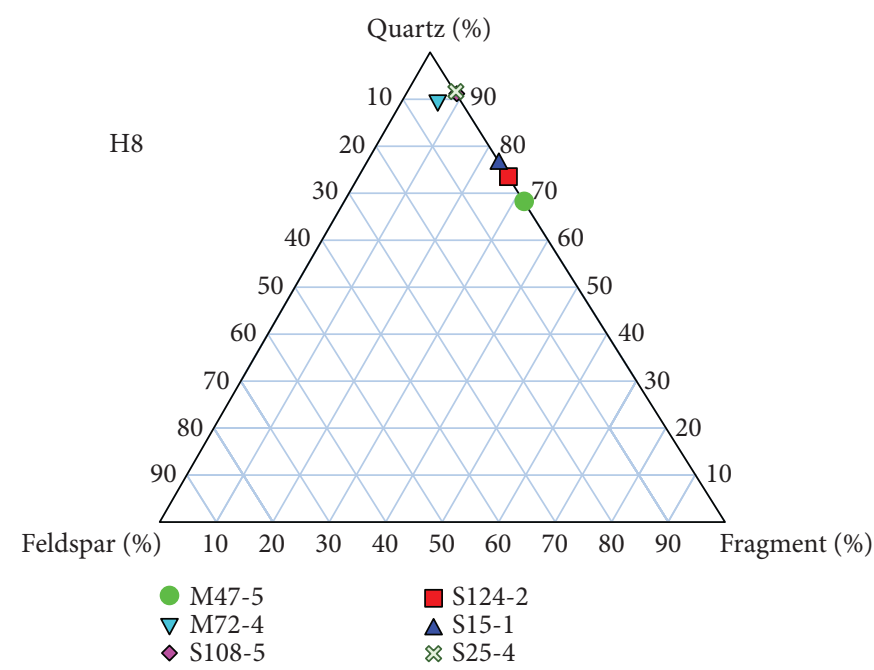

(b)

FIGURE 3: The mineral composition of samples: (a) Taiyuan formation; (b) H8 formation.

content (15\%) in $\mathrm{H} 8$ formation. The total clay content in Taiyuan formation can be as high as $31.6 \%$. The total clay content can be as low as $3.6 \%$ in $\mathrm{H} 8$ formation.

For analyzing the influence of clays on formation damage, the percent of different types of clays is shown in Figure 5. In Taiyuan samples, the main clays are illite and illite/smectite mixed layer. Simultaneously, the illite content is the main component in Taiyuan formation, while the kaolinite and chlorite can be neglected. However, the content of different clays of $\mathrm{H} 8$ formation is extremely different with that of Taiyuan formation. Chlorite is much higher than other clays and is about half of the clays. The weight percent of illite/smectite mixed layer and kaolinite is very similar.

3.3. Casting Thin Section. The casting thin section was shown in Figure 6. In Figure 6(a), there is nearly no pore in this area. From its perpendicular-polarized light in Figure 6(b), it is clear that the particles squeeze each other tightly and it belongs to concavo-convex contact. It indicates that this area endures strong compression force. In Figure 6(c), there are some large pores, which can be $154 \mu \mathrm{m}$. From its perpendicular-polarized light in Figure 6(d), it also shows that there are strong compression characteristics. In Figure 6(e), there is a large pore and clays exist near this pore, which is displayed with multicolor in Figure 6(f). In Figure 6(g), there are some pores and a big pore is located in the middle of this picture. From its perpendicularpolarized light, many particles exist in this area; the average particle size is about $369 \mu \mathrm{m}$.

In Figure 7(a), there are small cracks, which belong to an intergranular seam. Not all cracks are connected. From its perpendicular-polarized light picture in Figure 7(b), there are particles which were intersected by fracture. In Figure $7(\mathrm{c})$, there are some small cracks which are similar 


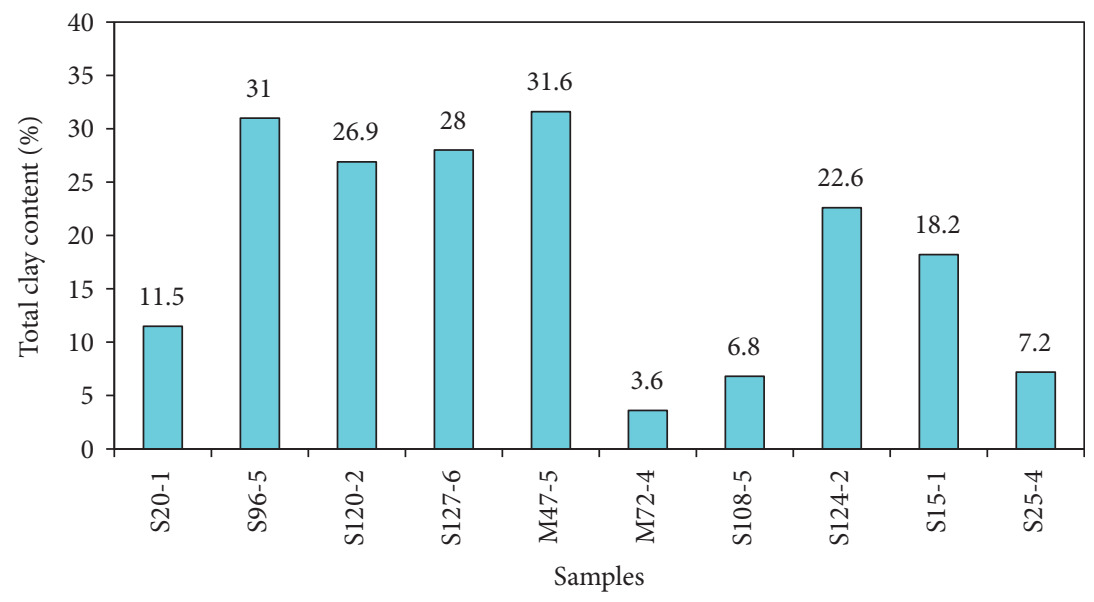

Figure 4: Samples' total clay content.

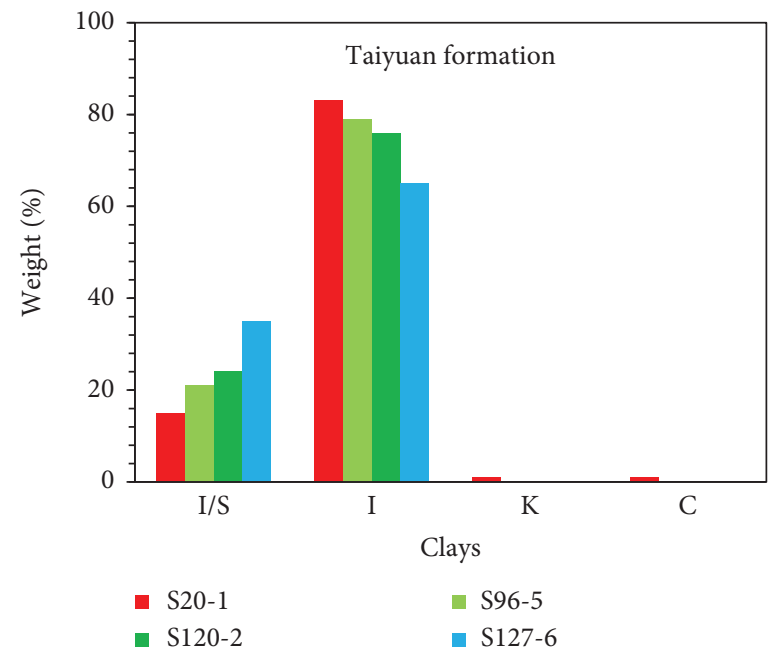

(a)

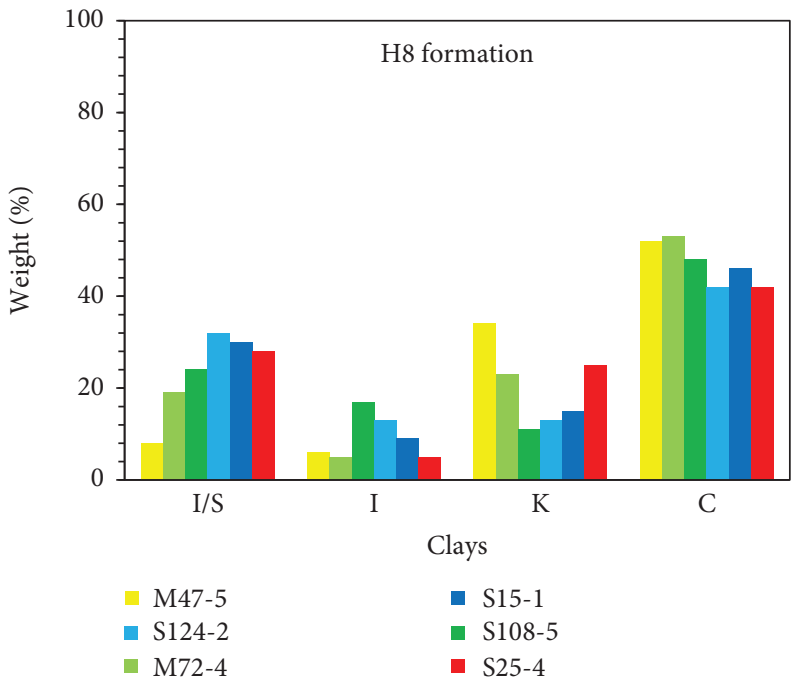

(b)

Figure 5: The content of different clays: (a) Taiyuan formation; (b) H8 formation.

to Figure 7(a). In its perpendicular-polarized light picture in Figure 7(d), strong compression characteristics exist. In Figure $7(\mathrm{e})$, there are also intergranular seam and no large pores. From Figure 7(f), there are some illites. There is no pore in Figure $7(\mathrm{~g})$. It indicates that this area is very tight. From its perpendicular-polarized light picture in Figure $7(\mathrm{~h})$, it shows that strong compression appears.

3.4. SEM Analysis. The scanning electronic microscope (SEM) in Taiyuan formation was shown in Figure 8. In Figure 8(a), there are some nanocracks and micropores. Lots of illite and chlorite exist in this area. From Figure 8(b), some illite exist and there are microcracks, which can be as large as $1.8 \mu \mathrm{m}$. The big crack penetrates the illite area. In Figure 8(c), there are many pores, which can be as large as $324 \mathrm{~nm}$. In Figure $8(\mathrm{~d})$, this area is full of illite. Two cracks penetrate this area. This big crack can be $718 \mathrm{~nm}$. In Figure 8(e), there are three long cracks. The wide part of the big crack can be $6 \mu \mathrm{m}$. In Figure $8(\mathrm{f})$, there are many pores, which are nearly round. In Figure $8(\mathrm{~g})$, there are big cracks, which intertwine with clays. Some cracks were filled with small particles. In Figure $8(\mathrm{~h})$, there are many small cracks, which have a width of $36 \mathrm{~nm}$. A big pore connected with crack, which has a width of $536 \mathrm{~nm}$ and a length of $1.3 \mu \mathrm{m}$. In Figure 8(i), there are also many pores. The pore size can be $314 \mathrm{~nm}$ and $192 \mathrm{~nm}$.

H8 formation SEM pictures were shown in Figure 9. There are many small cracks in Figure 9(a). One big crack can be $909 \mathrm{~nm}$. There are some small pores. In Figure 9(b), there are lots of illites and two cracks appear in this area. The big pore located in the joint of two cracks has a width of $16.43 \mu \mathrm{m}$. In Figure 9(c), there are lots of small pores. One pore can be $630 \mathrm{~nm}$. Two cracks exist in Figure 9(d). The big crack has a width of $500 \mathrm{~nm}$. In Figure 8(e), there are small cracks and illite. One big pore near clays has a diameter of $1.78 \mu \mathrm{m}$. In Figure 9(f), there are many pores in this area, and one pore has a diameter of $390 \mathrm{~nm}$. In Figure $9(\mathrm{~g})$, there are some illites and a small crack which has a width of $284 \mathrm{~nm}$. In Figure 9(h), this area is full of clays 


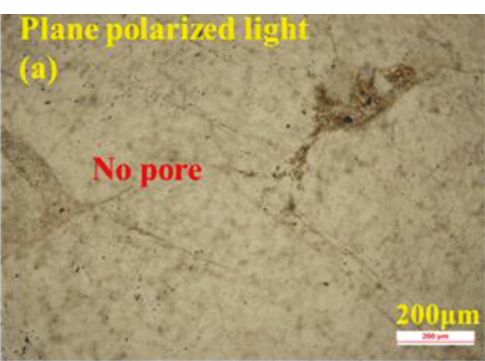

(a)

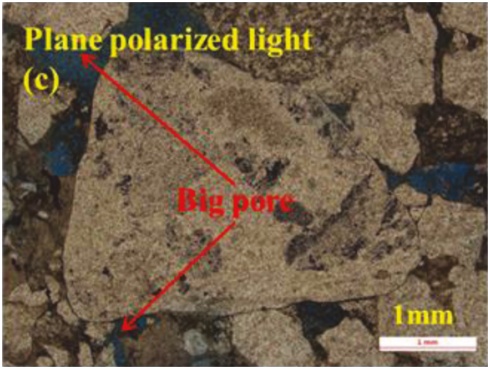

(c)

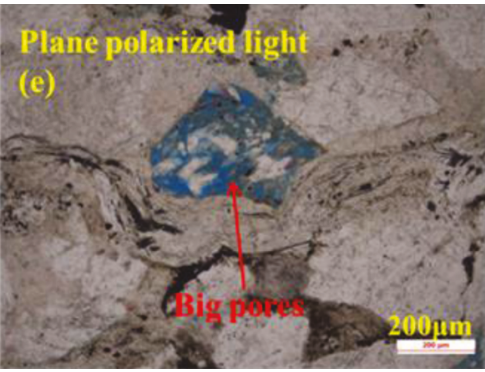

(e)

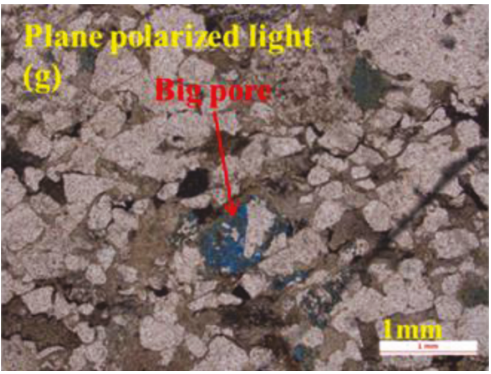

(g)

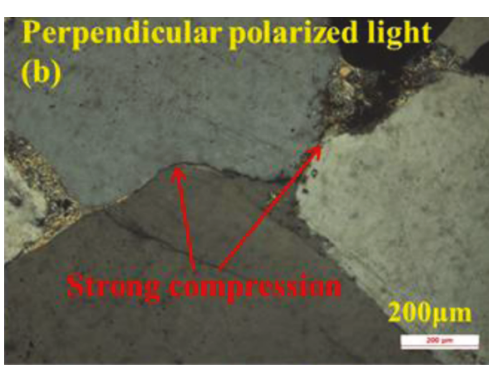

(b)

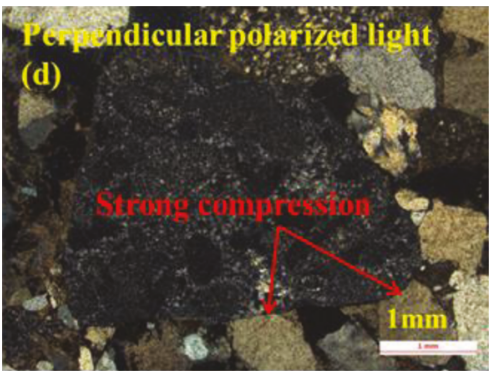

(d)

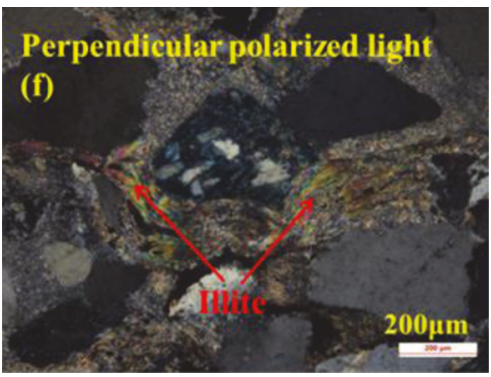

(f)

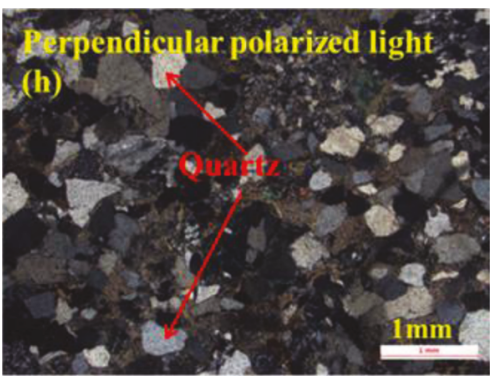

(h)

Figure 6: The casting thin section: (a)-(e) belong to S20-5 and (f)-(h) belong to S96-3. The left picture and the right picture belong to the same area.

and cracks. The width of crack can be $1.83 \mu \mathrm{m}$. In Figure 9(i), there are some pores and the diameter can be $801 \mathrm{~nm}$.

3.5. Permeability Tress Sensitivity. Permeability stress sensitivity has been researched in many previous papers [64]. From Figure 10, it is clear that the permeability decreases quickly with increasing confining pressure. During the stress-releasing process, permeability could not recover to the initial permeability. When sample experiences second stress loading and unloading, the first unloading and second unloading nearly overlapped. All sample permeability has been changed into dimensionless permeability.
For further analysis of stress sensitivity, $K_{0}, K_{01}$, and $K_{1}$ are shown in Figure 10, respectively. $K_{0}$ is the initial permeability at $5 \mathrm{MPa}$ of first loading; $K_{01}$ is the permeability at $25 \mathrm{MPa}$ of first loading; $K_{1}$ is the permeability at $5 \mathrm{MPa}$ of first unloading. Therefore, we can obtain the permeability loading loss from $5 \mathrm{MPa}$ to $25 \mathrm{MPa}$ as well as the permeability recovery loss from $5 \mathrm{MPa}-25 \mathrm{MPa}-5 \mathrm{MPa}$.

The permeability loading loss is defined as

$$
\frac{K_{0}-K_{01}}{K_{0}} \times 100 \% \text {. }
$$




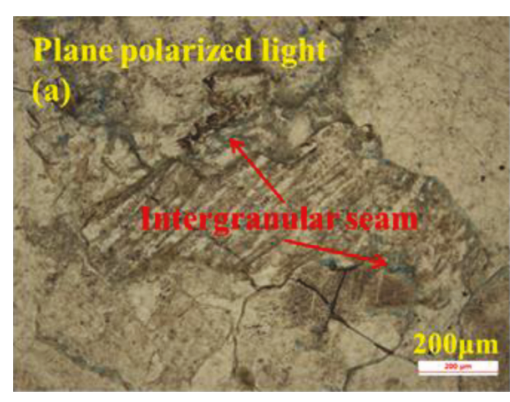

(a)

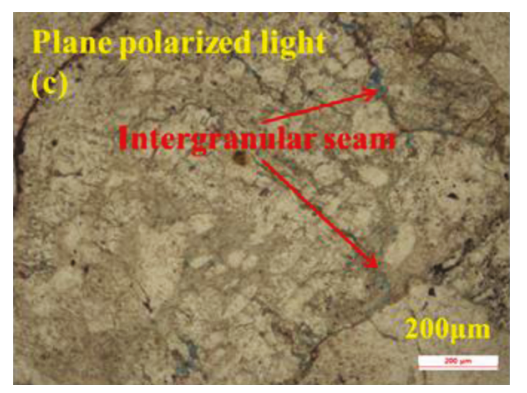

(c)

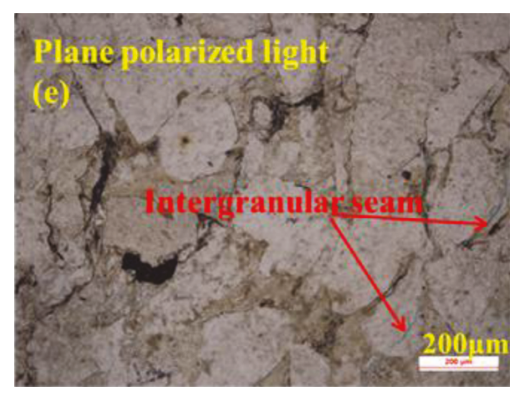

(e)

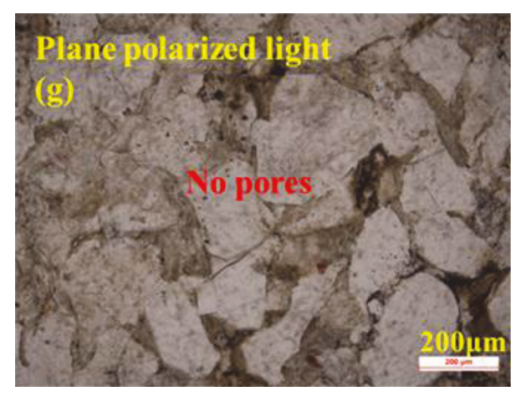

(g)

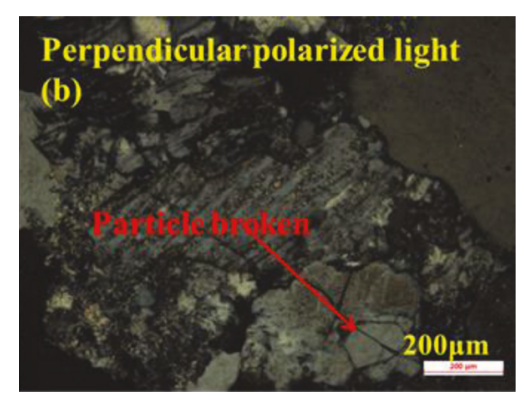

(b)

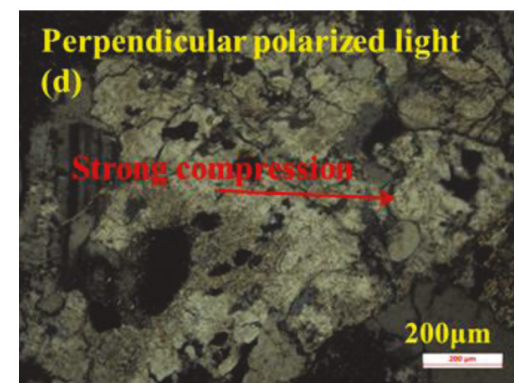

(d)

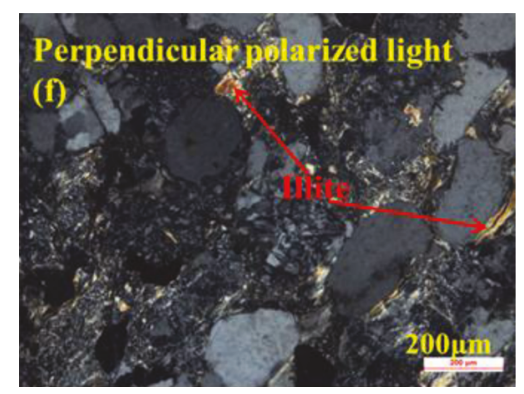

(f)

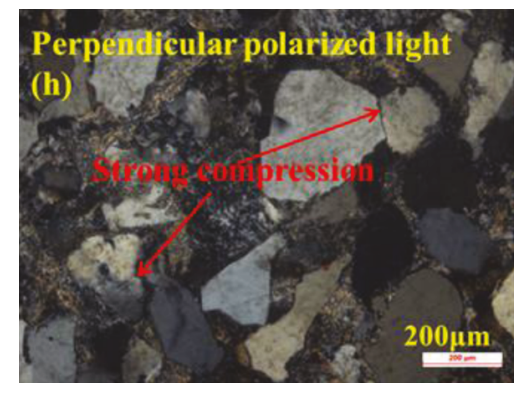

(h)

Figure 7: The casting thin section: (a)-(e) belong to M72-5 and (f)-(h) belong to S123-1. The left picture and the right picture belong to the same area.

The permeability recovery loss is defined as

$$
\frac{K_{0}-K_{1}}{K_{0}} \times 100 \%
$$

In Figure 10, the permeability loading loss is $71.3 \%$ and the permeability recovery loss is $40 \%$ in S20-6, which indicates that nearly half of permeability could not recover. In S30-3, the permeability loading loss is $75.5 \%$ and the permeability recovery loss is $36.1 \%$. In S96-1, the permeability loading loss is $66 \%$ and the permeability recovery loss is $36.8 \%$. In S120-4, the permeability loading loss is $78.2 \%$ and the permeability recovery loss is $43 \%$. Therefore, Taiyuan formation has strong permeability stress sensitivity.

In Figure 11, H8 formation has similar characteristics with Taiyuan formation. The permeability loading loss is $85.8 \%$ and the permeability recovery loss is $47.3 \%$ in M47-2, which also indicates that nearly half of permeability could not recover. In M72-4, the permeability loading loss is $87 \%$ and the permeability recovery loss is $59.1 \%$. In S108-5, the permeability loading loss is $66 \%$ and the 


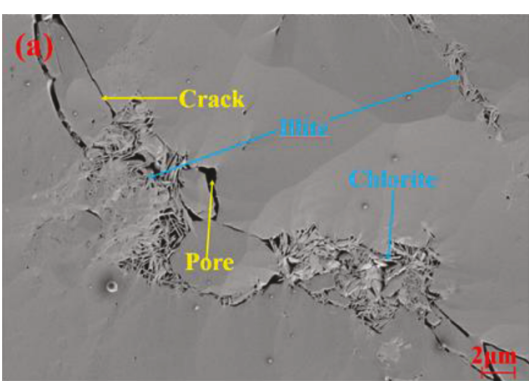

(a)

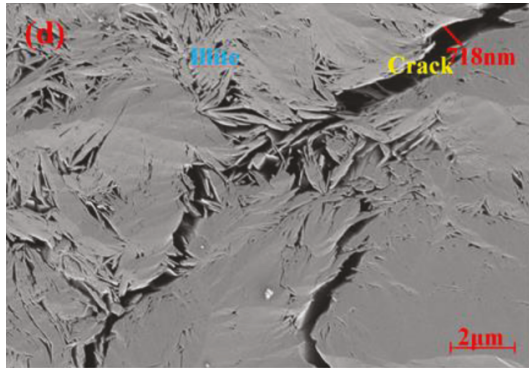

(d)

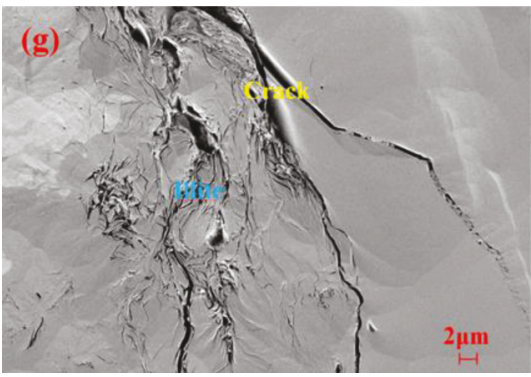

(g)

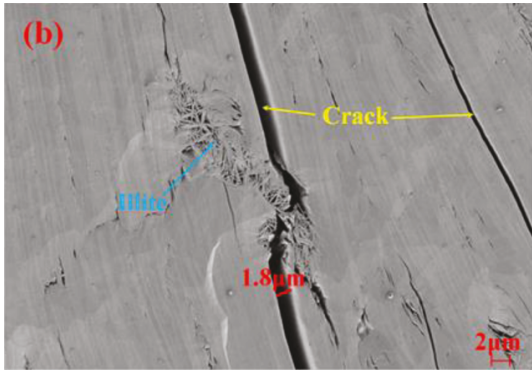

(b)

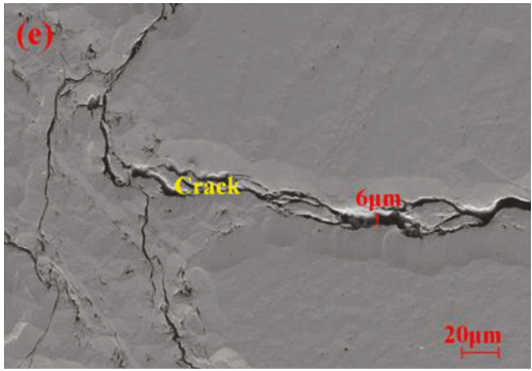

(e)

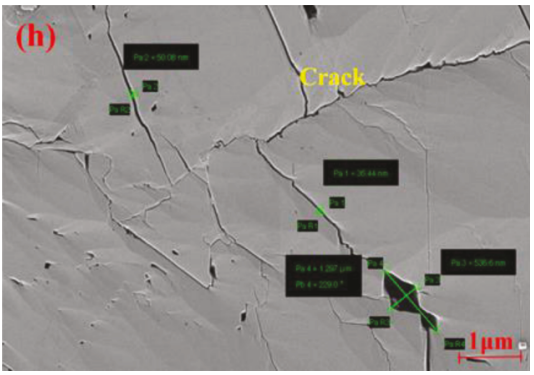

(h)

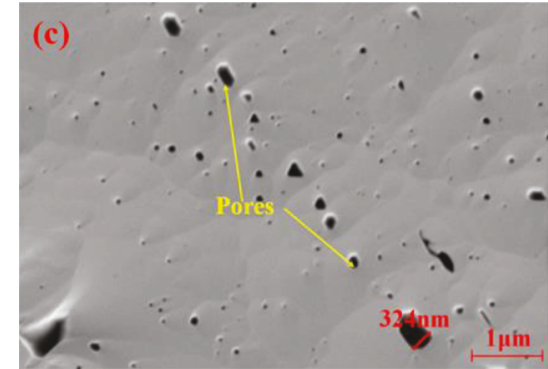

(c)

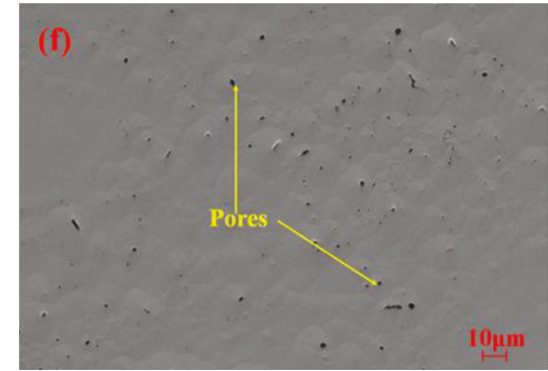

(f)

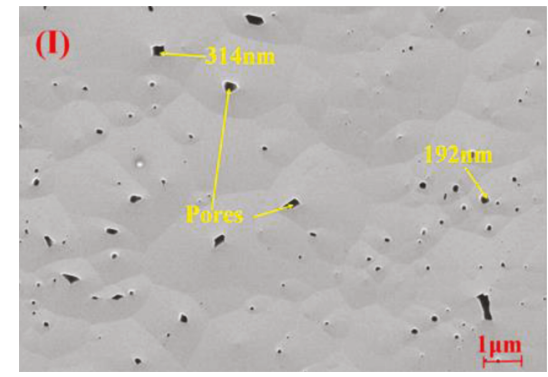

(i)

Figure 8: The SEM picture: (a)-(c) belong to S30-2, (d)-(f) belong to S120-1, and (g)-(i) belong to S126-2.

permeability recovery loss is $26.4 \%$. In S123-3, the permeability loading loss is $88.8 \%$ and the permeability recovery loss is $43.9 \%$. It also shows severe permeability stress sensitivity damage.

3.6. Sample Expansion. The interaction between clays and fracturing liquid has strong impact on the formation damage. From Figure 12, volcanic rock has strong capacity for clay expansion. The expansion rate can reach to $50 \%$ in about 3 hours. Shale rock expansion nearly keeps constant at 1 hour in WFZ, which is about $30 \%$. The LJP shale rock expansion is far weaker than the WFZ. It reached stability about $20 \mathrm{~min}$, and its expansion rate is about $15 \%$. Tight sand has less expansion capacity. All sample expansion rate is no larger than $20 \%$. The expansion can quickly approach to constant in less than 1 hour.

In Figure 13, the relationship between expansion rate at 3 hours and clay content has been shown. Expansion rate has a positive relationship with the clay content. Volcanic rocks have strong expansion capacity due to its high clay content. Tight sand has weak expansion rate due to its low clay content.
3.7. Nitrogen Displacement. Displacement experiment has been used to appraise the aqueous damage removal capacity in laboratory, which can simulate the reservoir condition during the flowback or production process. Two types of displacement experiments have been tested, including displacement with time and displacement with different displacing pressure.

3.7.1. Displacement Efficiency with Time. The S20-4 displacement was shown in Figure 14(a). The permeability recovery rate increases with displacing time, and liquid saturation decreases with displacing time. At initial condition, the liquid saturation is $58.14 \%$ at $5 \mathrm{MPa}$ displacement pressure and $67.85 \%$ at $7 \mathrm{MPa}$ displacement pressure. The liquid saturation decreases greatly at beginning 0.5 hour, which reduced to less than half of initial liquid saturation. When displacement time reaches to 10 hours, the liquid saturation approached to $8.69 \%$ in $5 \mathrm{MPa}$ and $5.13 \%$ in $7 \mathrm{MPa}$. At the same time, the permeability recovery rate increases to $67.53 \%$ in $5 \mathrm{MPa}$ and $72.82 \%$ in $7 \mathrm{MPa}$. It shows that this rock has strong aqueous phase trapping removal capacity. The reason is that it has less clay content, which is only 


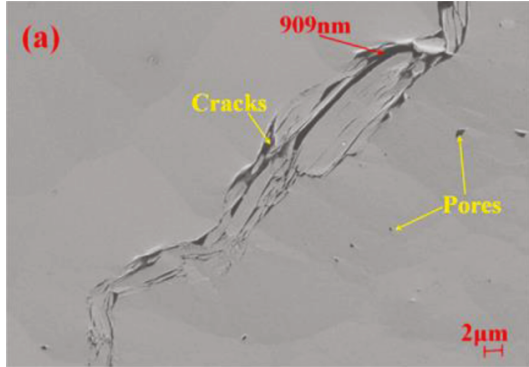

(a)

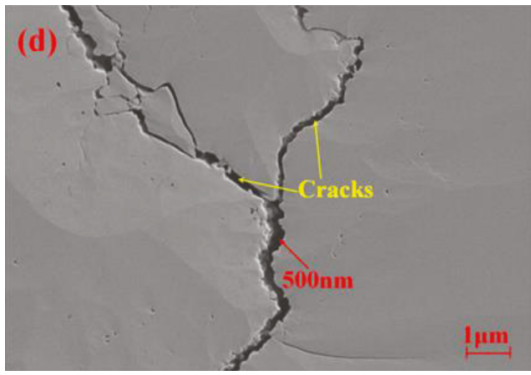

(d)

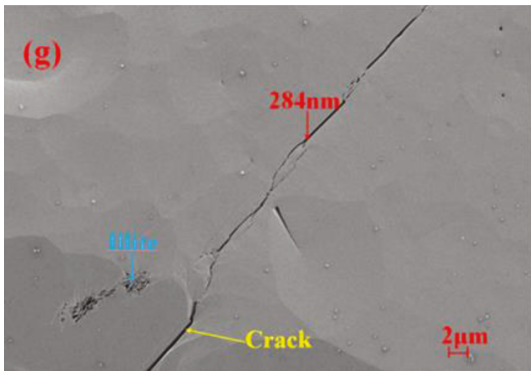

(g)

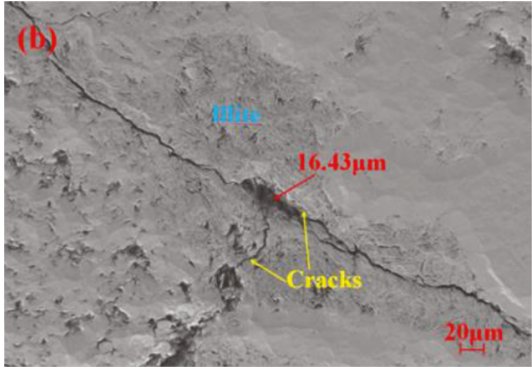

(b)

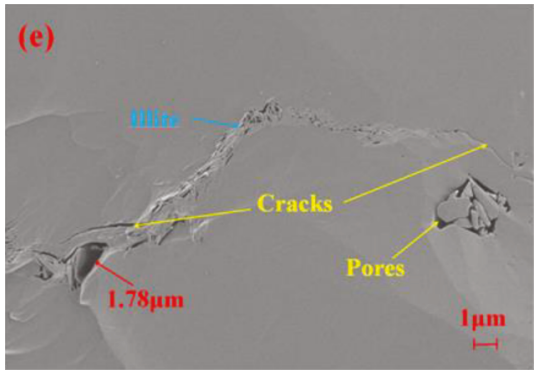

(e)

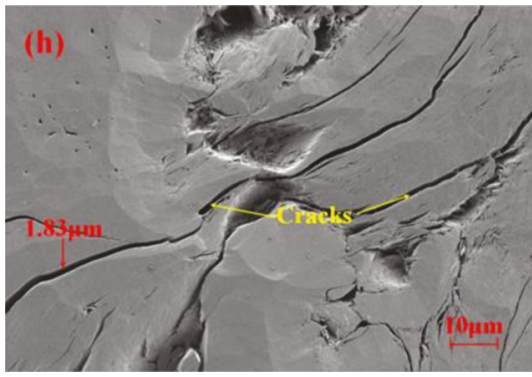

(h)

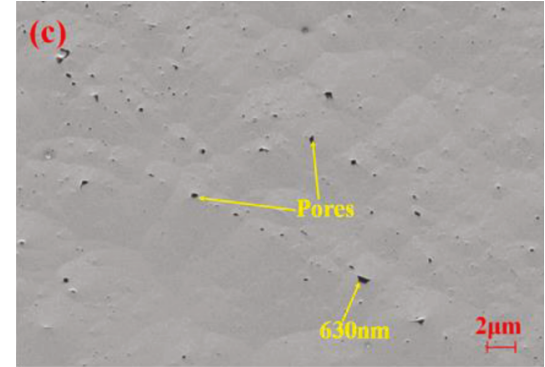

(c)

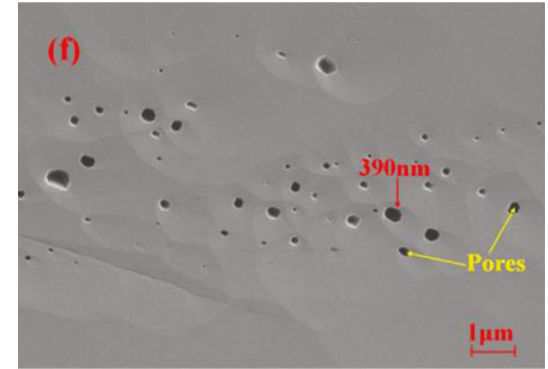

(f)

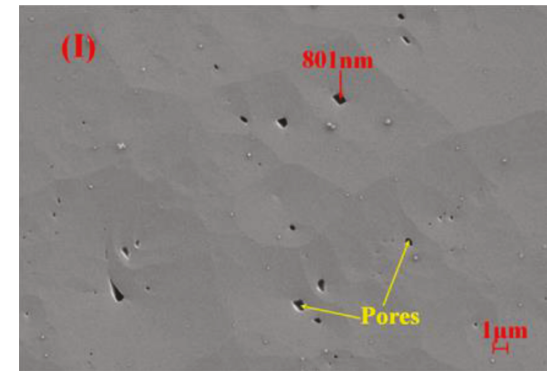

(i)

Figure 9: The SEM picture: (a)-(c) belong to M47-3, (d)-(f) belong to S133-4, and (g)-(i) belong to S31-1.

11.5\% from Figure 4. The sample S20-1 and S20-4 have similar mineral components because these two samples were taken from close area. From Figure 14(b), the displacement of S96-3 was shown. There are two displacement pressures, including $15 \mathrm{MPa}$ and $20 \mathrm{MPa}$. The initial liquid saturation is $53.13 \%$ and $58 \%$. At initial displacement time, the permeability nearly keeps constant. It shows that liquid decreasing has no impact on rock permeability. When displacement time reaches to 2 hours, permeability still keep stability at $15 \mathrm{MPa}$. However, the permeability increases at $20 \mathrm{MPa}$. It shows high pressure has more capacity for gas flowing. At last, the liquid saturation is $31.85 \%$ at $15 \mathrm{MPa}$ and $31.84 \%$ at $20 \mathrm{MPa}$. However, the permeability recovery rate is only $0.4 \%$ at $15 \mathrm{MPa}$ and 0.24 at $20 \mathrm{MPa}$, which can be neglected. The weak permeability recovery rate is closely related to the clay content, which is $31 \%$. The more clay content is, the lesser the displacement efficiency is. In Figure 14(c), the displacement of S120-4 was shown. Three displacement pressures were chosen, including $7 \mathrm{MPa}, 10 \mathrm{MPa}$, and $15 \mathrm{MPa}$. The liquid saturation change is similar among three displacing pressures. At last, the liquid saturation curves nearly overlapped each other. However, the permeability recovery rate is different. In the end, the permeability recovery rate is $30.46 \%, 40.92 \%$, and $55.89 \%$, respectively. This sample has high flowback rate, which is caused by good pore connection.

In Figure 15(a), two displacement pressures were chosen for testing, including $10 \mathrm{MPa}$ and $15 \mathrm{MPa}$. At initial time, the liquid decreases quickly. At 1 hour, the permeability has no increase at $10 \mathrm{MPa}$ and a little increase at $15 \mathrm{MPa}$. At last, the liquid saturation is $39.28 \%$ at $10 \mathrm{MPa}$ and $35.67 \%$ at $15 \mathrm{MPa}$. At the same time, the permeability recovery rate approach to $3.41 \%$ at $10 \mathrm{MPa}$ and $6.07 \%$ at $15 \mathrm{MPa}$. This low flowback rate and permeability recovery rate may be caused by micro-nanopores. In Figure 15(b), there are three displacement pressures, including $3 \mathrm{MPa}, 5 \mathrm{MPa}$, and $7 \mathrm{MPa}$. At 0.5 hour, the liquid saturation decreases greatly. The liquid saturation is $25.13 \%, 28.32 \%$, and $27.38 \%$, respectively. At the same time, the permeability recovery rate is $49.41 \%, 49.78 \%$, and $50.12 \%$. When displacement time reaches to 6 hours, the liquid saturation and permeability recovery rate nearly keep stability. At this displacement time, the liquid saturation is $10.23 \%, 9.51 \%$, and $7.86 \%$. The permeability recovery rate is $68.42 \%, 71.19 \%$, and $76.75 \%$. The high flowback rate is due to its relative low clay content, which is $18.2 \%$. 


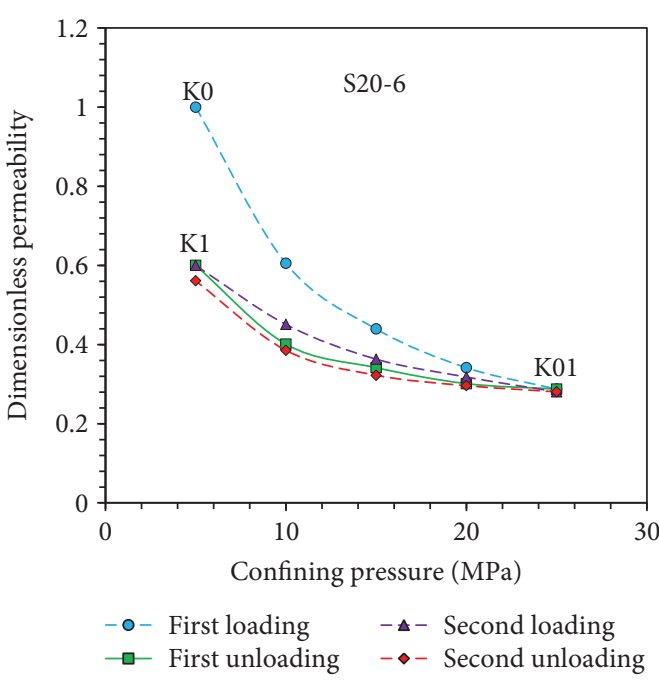

(a)

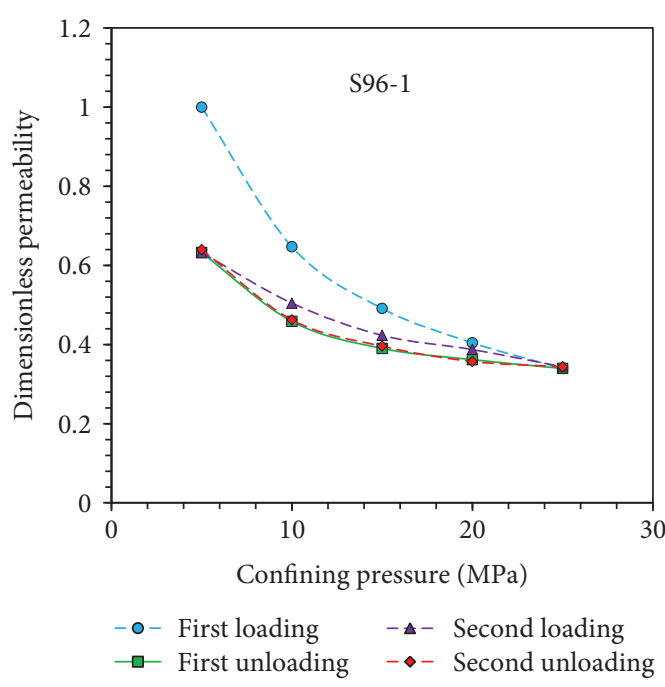

(c)

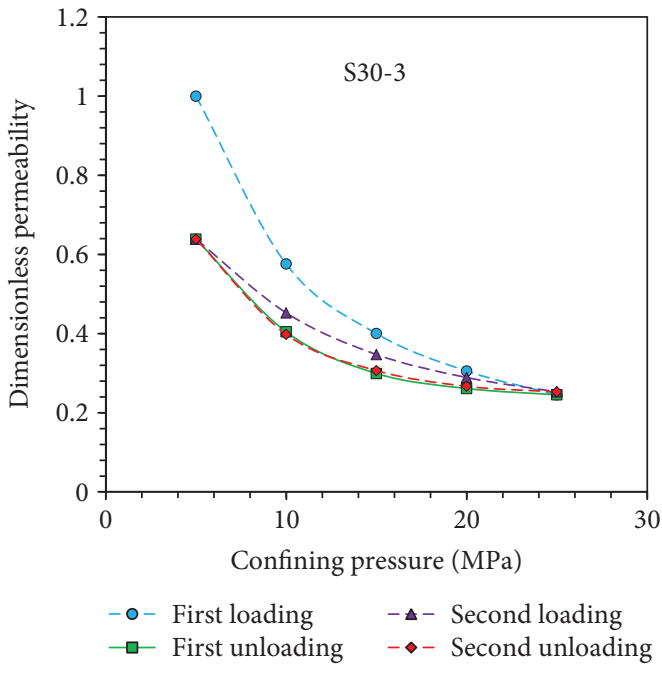

(b)

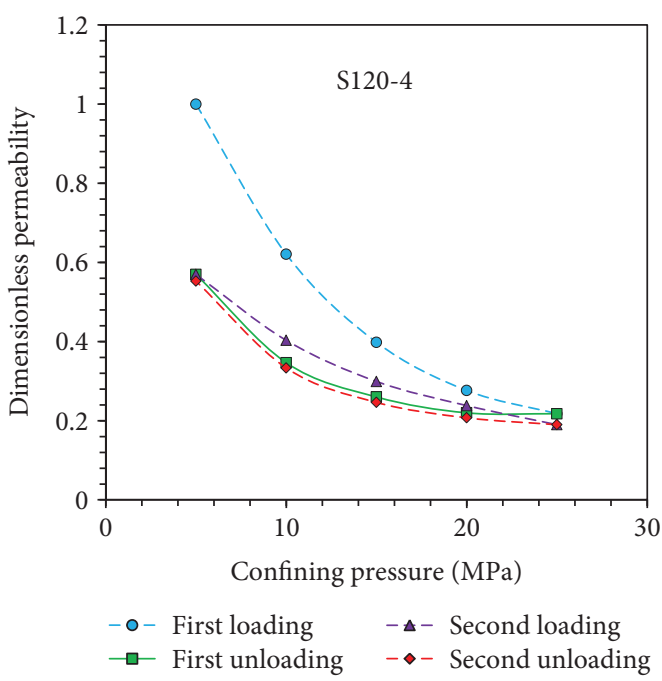

(d)

FiguRe 10: Stress sensitivity of H8 formation.

3.7.2. Displacement Efficiency with Displacing Pressure. In Figure 16(a), the relationship between liquid flowback rate and displacement pressure was shown. Sample S15-6 and S20-4 have high flowback rate. It is closely related to the permeability. High permeability usually has high flowback rate. The flowback rate become stable at $15 \mathrm{MPa}$ in S20-4, which is about $85.31 \%$. Sample M72-3 and S123-1 have low flowback rate, because both have low permeability. The flowback rate is $21.66 \%$ and $22.42 \%$ at $10 \mathrm{MPa}$, respectively. However, sample S133-4 has relatively high flowback rate, even though it has similar permeability as M72-3 and S123-1. Its flowback rate can reach to $44.49 \%$ at $10 \mathrm{MPa}$. In Figure 16(b), the permeability recovery rate with different displacement pressure was investigated. Both S15-6 and S20-4 have high-permeability recovery rate, especially S15-6, which can reach to $95.63 \%$ at $7 \mathrm{MPa}$. There is no permeability increase in S120-4 when displacement pressure is less than $3 \mathrm{MPa}$. Both sample M72-3 and S123-1 have similar permeability, so that the permeability recovery rate curve has similar characteristics. S133-4 has the lowest initial permeability, so that its permeability recovery rate curve is at the lower part. Therefore, displacement efficiency is closely related to the initial permeability and displacement pressure.

\section{Discussions}

Ordos basin has large amount of tight sand gas. Hydraulic fracturing has been carried out to exploit this kind of natural gas. However, there is severe aqueous phase damage due to its low permeability, which greatly influence its effective development. For better developing this type of natural gas in tight sand, the formation characteristics have been investigated as well as its influence on the fracturing liquid flowback and permeability recovery rate. Through XRD analysis, it shows that there are lots of quartz and clays, which make the wettability more water wet. Thus, the liquid retention is 


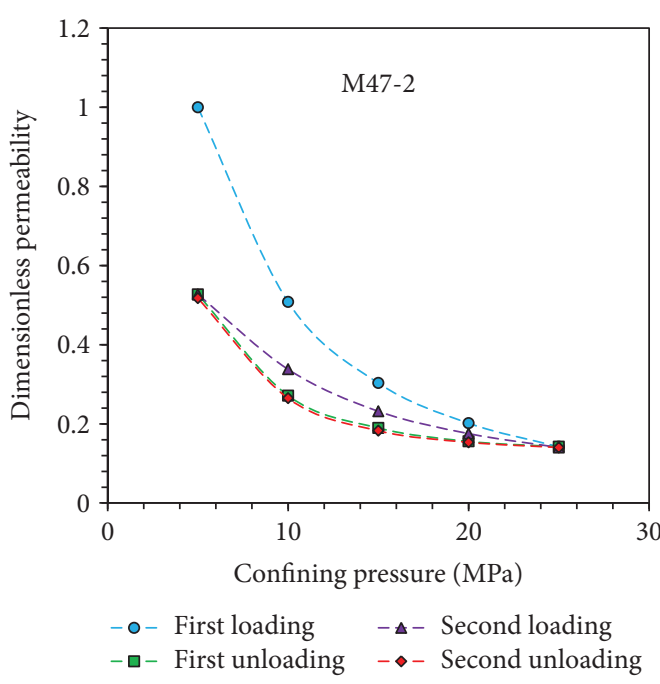

(a)

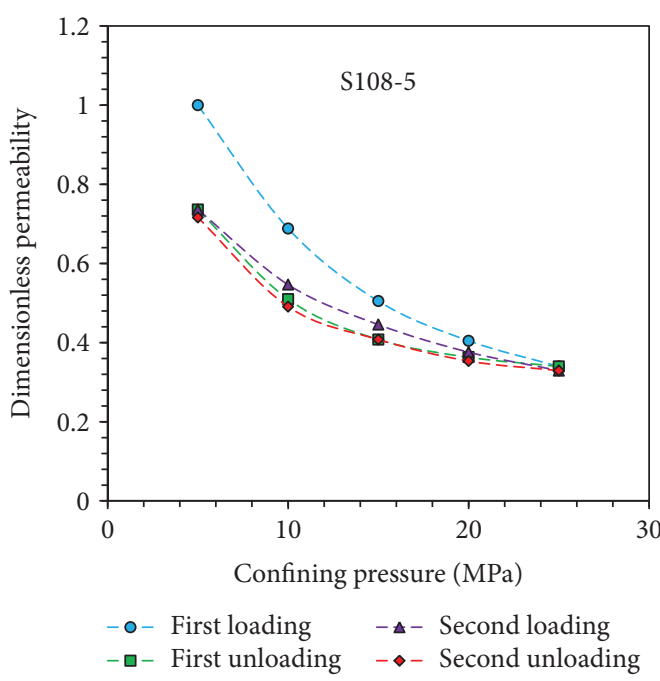

(c)

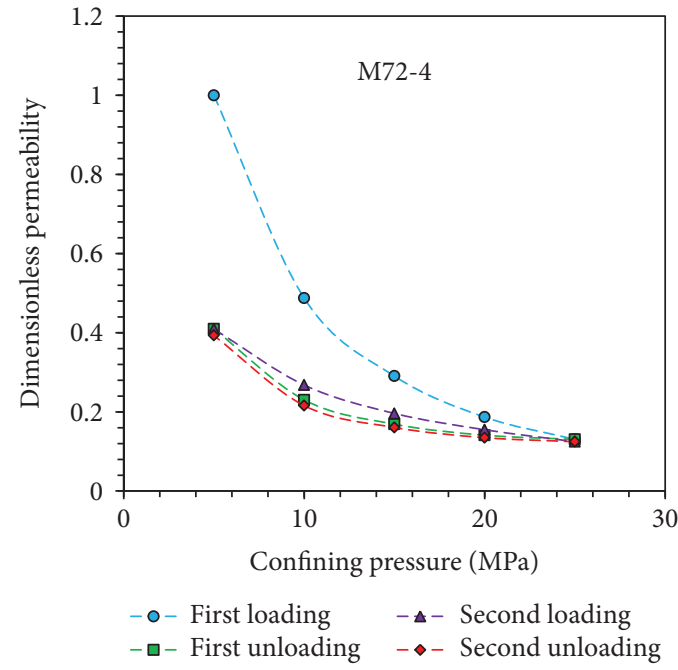

(b)

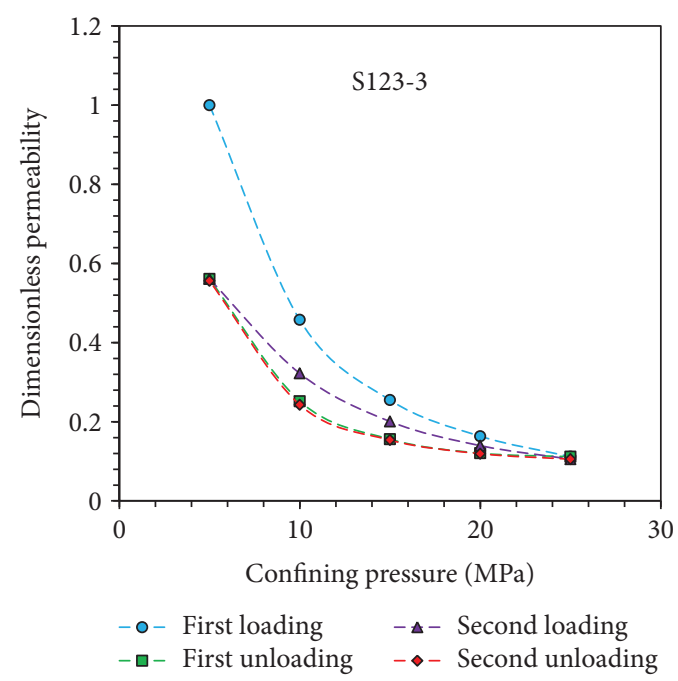

(d)

FIGURE 11: Stress sensitivity of Taiyuan formation.

more severe, and high displacement pressure was needed to reduce aqueous phase, which make it more difficult to move the aqueous phase out of formation. For further understanding the microcharacteristics of tight sand, both the casting thin section and scanning electron microscope have been used to reflect the pore characteristics and particle contact characteristics. The different pores and cracks can be shown in casting thin section, usually the microscale. Pores and cracks were filled with blue color. In Taiyuan formation, there are many big pores, which is beneficial to gas flowing and gas displacing liquid during flowback. There are lots of micro-nanocracks, which are sensitive to stress. The cracks are likely close during development, which was simulated in laboratory by permeability stress sensitivity. The permeability decreases quickly at the early loading process and damages greatly when confining pressure reach to subsurface pressure. More than half of the permeability has lost. It indicates that the productivity will be influenced greatly when the reservoir gas pressure decreases during production. After the permeability damage, even though the gas pressure increases to the initial condition, there is still severe permeability damage, which was simulated by the unloading process. This phenomenon indicates that once the microcracks closed, it is difficult to reopen again. This characteristic shows that the reservoir should keep the gas pressure during the production by injecting other gas. During unloading process, the permeability can increase gradually. When confining pressure return to the initial condition, the permeability increases greatly. It shows that permeability can increase by injecting gas after reservoir endures permeability loss by production process.

The gas displacement behavior is closely related to reservoir characteristics, and the efficiency for displacing the fracturing fluid out of formation has relationship with clays. Through the sample expansion experiment, it can be found that the sample expansion rate has positive 


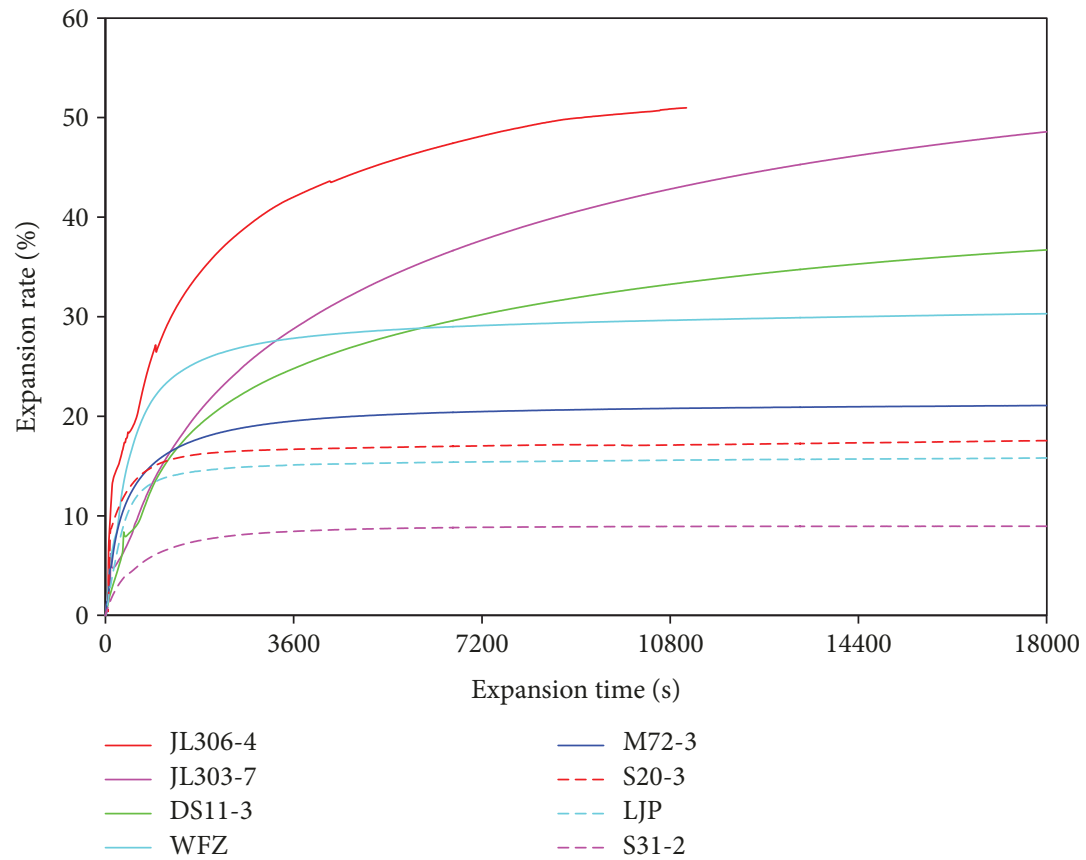

FIGURE 12: Sample expansion with time. JL306-4, JL303-7, and DS11-3 belong to volcanic gas sedimental rock; WFZ and LMX belong to shale gas rock.

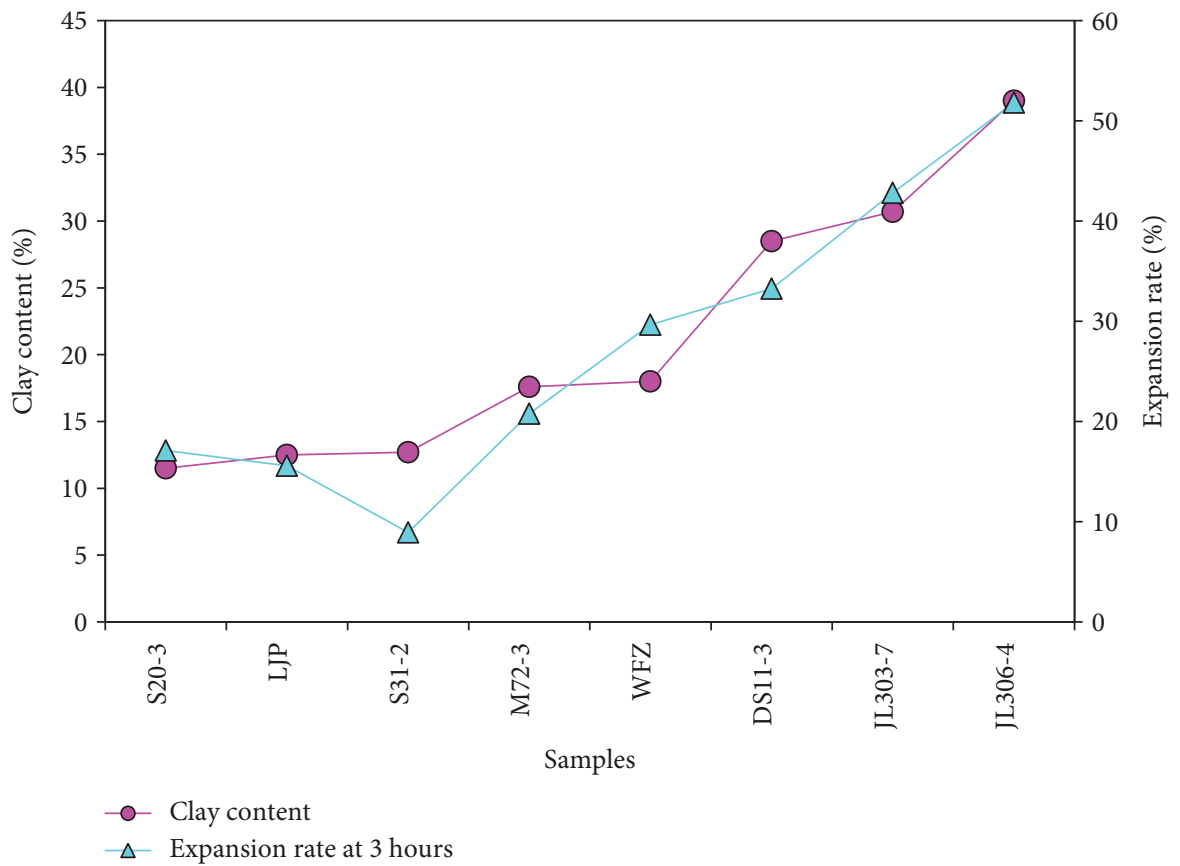

FIgURE 13: The relationship between expansion rate at 3 hours and clay content.

relationship with the clay content. Tight sand has less expansion rate when it is compared with volcanic gas rock and shale gas rock. Therefore, it has less formation damage caused by the clay expansion. During nitrogen displacement experiment, different clay percent has been considered. In most cases, the more clays the samples have, the more damage the formation will be. It means that there is less liquid flowback and less permeability recovery rate. The initial permeability has greatly influenced the liquid flowback. Usually, the larger the initial permeability, the higher the liquid flowback and permeability recovery rate. Some samples have similar initial permeability. However, there are different liquid flowback rate, which is likely caused by the different pore network. 


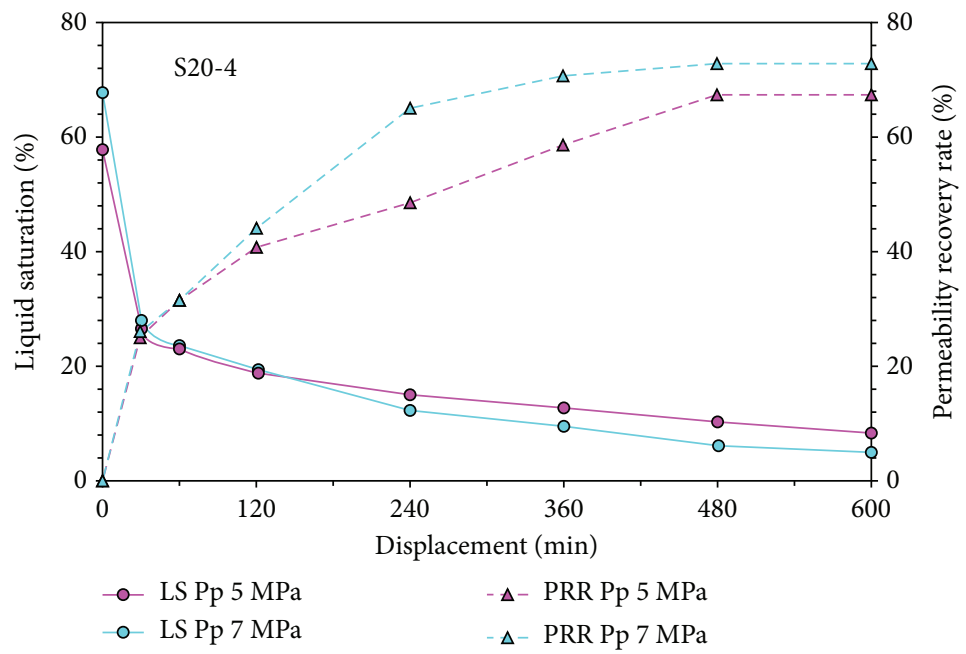

(a)

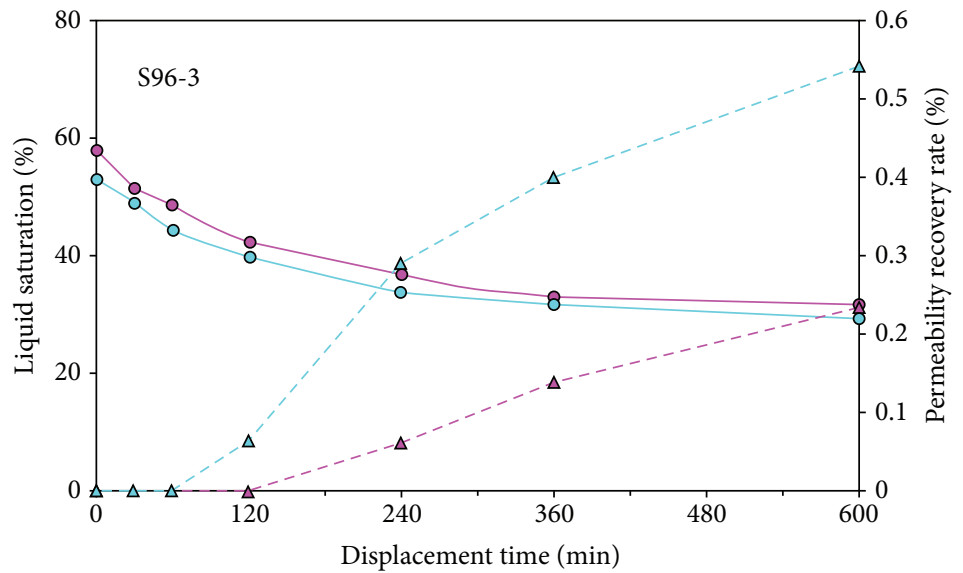

- $\quad$ LS Pp $15 \mathrm{MPa}$

- LS Pp $20 \mathrm{MPa}$

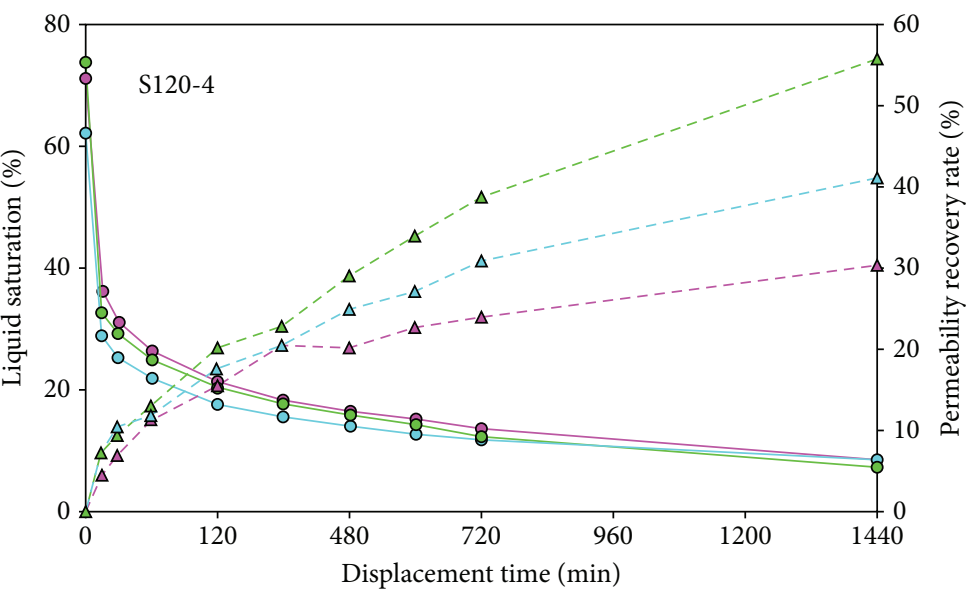

- - LS Pp $7 \mathrm{MPa}$

- L LS Pp $15 \mathrm{MPa}$

$\Delta-$ PRR Pp $10 \mathrm{MPa}$ $\triangle$ - PRR Pp $15 \mathrm{MPa}$

$\Delta$ - PRR Pp $20 \mathrm{MPa}$

(b)

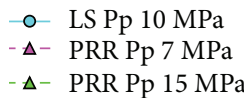

(c)

FIgURE 14: The variation of liquid saturation and permeability recovery rate with displacement time in Taiyuan formation. Confining pressure is $25 \mathrm{MPa}$. 


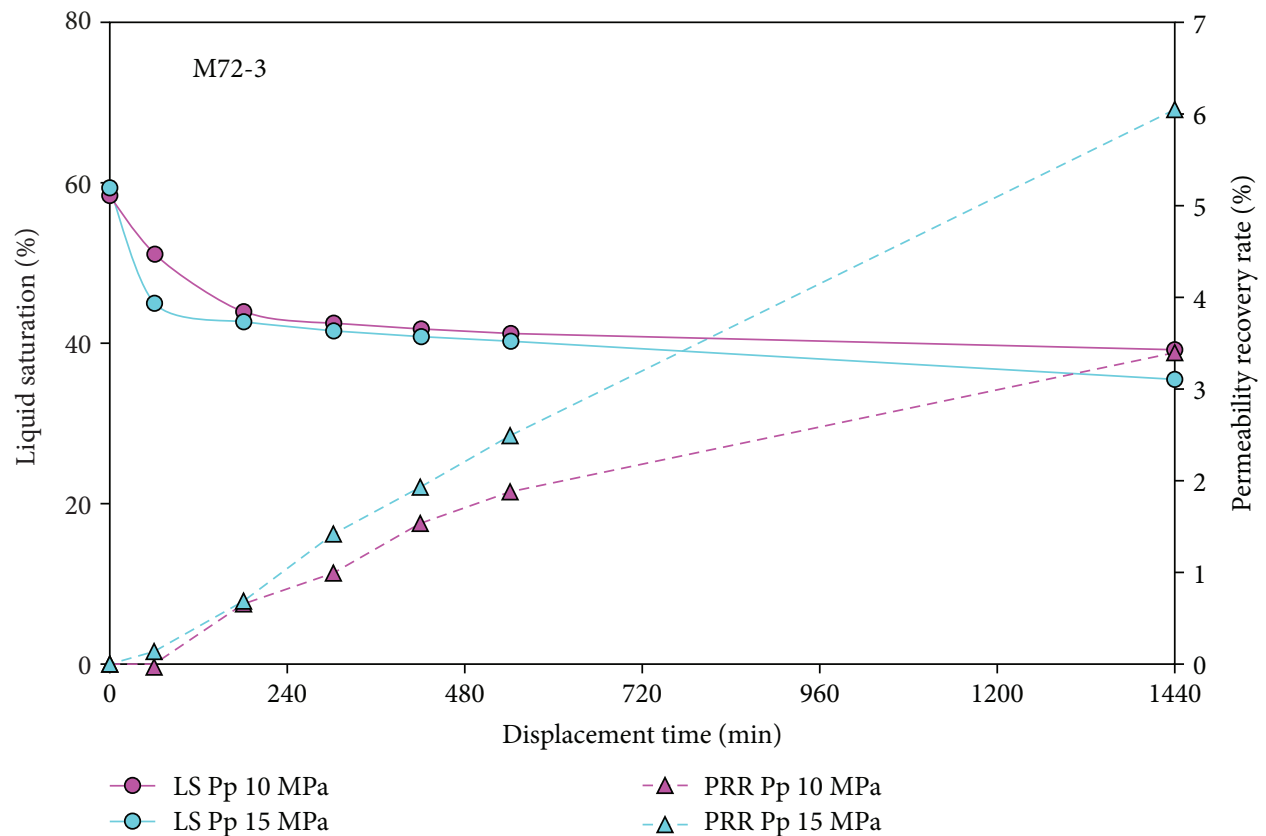

(a)

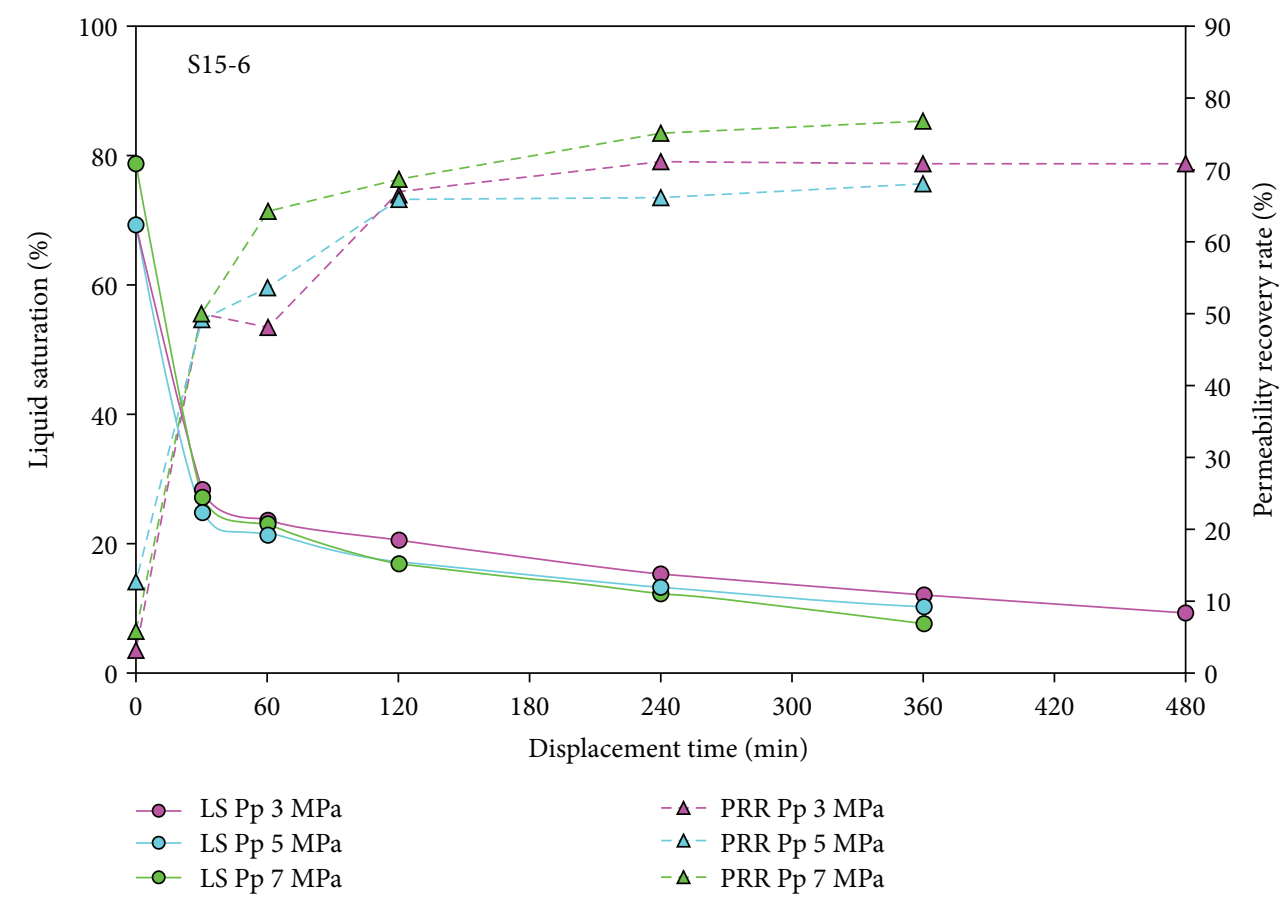

(b)

FIGURE 15: The variation of liquid saturation and permeability recovery rate with displacement time in H8 formation. Confining pressure is $25 \mathrm{MPa}$.

In order to further analyze the influence of porosity and permeability on fluid flow in rocks, the FZI* flow zone indicator was analyzed. The equation of FZI* is shown as follows $[65,66]$ :

$$
\mathrm{FZI}^{*}=0.0314 \sqrt{\frac{k}{\varnothing}}
$$

where $k$ is the permeability in $\mathrm{mD}$ and $\varnothing$ is the porosity in fraction.

In Figure 17, the sample FZI* was shown, and it varies from $0.033 \mu \mathrm{m}$ to $0.126 \mu \mathrm{m}$. The higher the $\mathrm{FZI}^{*}$ is, the better the fluid flow in rock is. This indicator has good relationship with the permeability recovery rate in Figure 16. Sample S15-6 has high-permeability recovery rate, which can reach to $95.63 \%$, and it also has high 


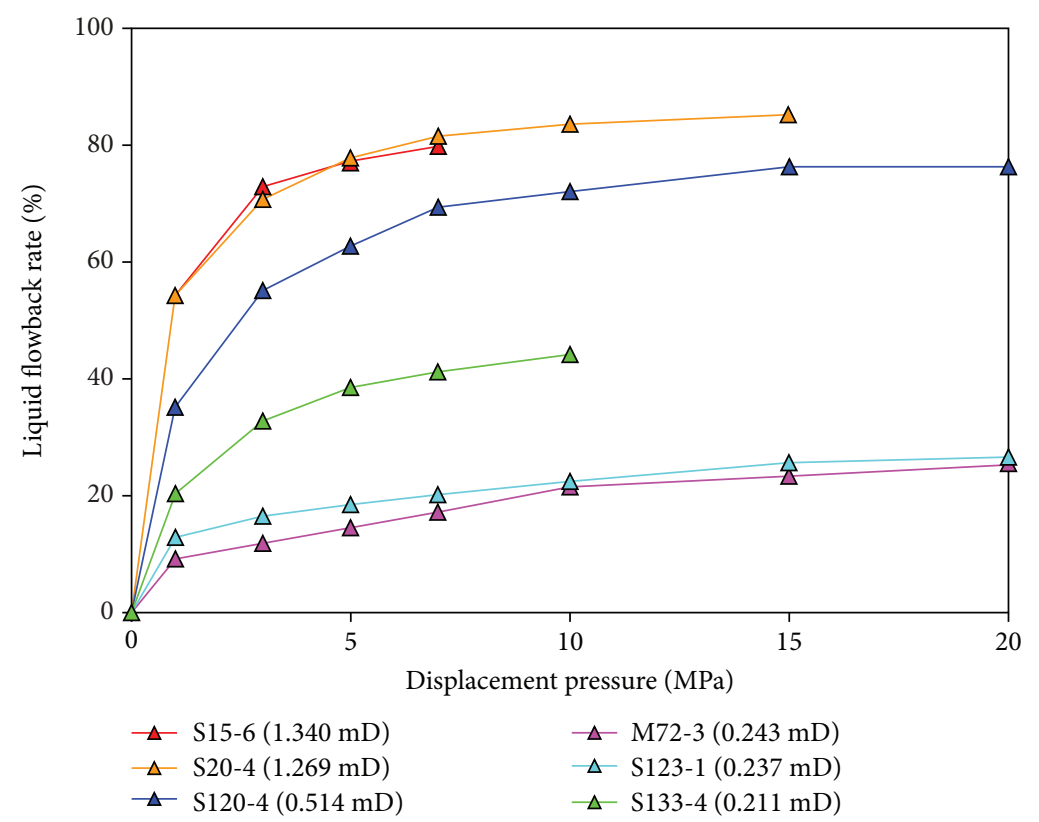

(a)

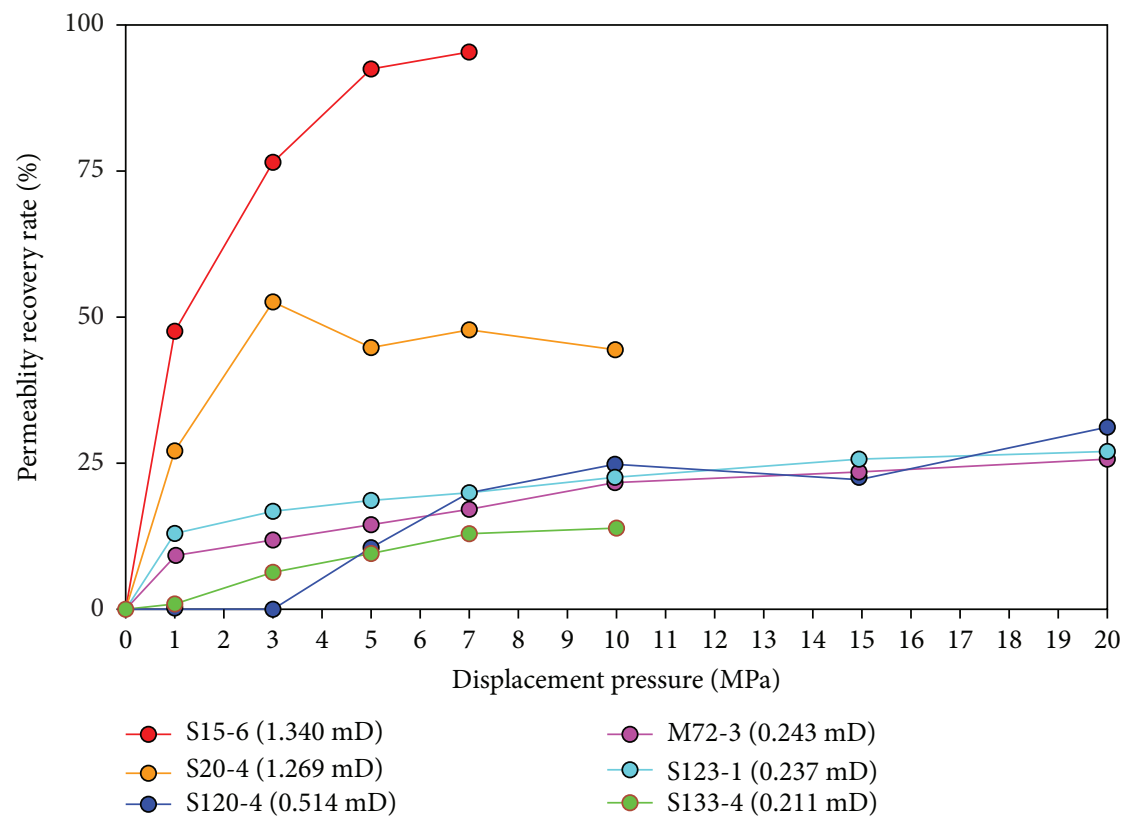

(b)

FIGURE 16: The variation of liquid flowback rate and permeability recovery rate with different displacement pressure. Confining pressure is $25 \mathrm{MPa}$.

FZI*, which is $0.125 \mu \mathrm{m}$. Sample S20-4 has the permeability recovery rate of $85.31 \%$, and it has the $\mathrm{FZI}^{*}$ of $0.116 \mu \mathrm{m}$. Sample S133-4 has low permeability recovery rate, and it has the low FZI*, which is $0.046 \mu \mathrm{m}$. Therefore, the higher the $\mathrm{FZI}^{*}$ is, the higher the permeability recovery rate is.

Through our research, in order to increase the fracturing fluid flowback rate and permeability recovery rate in the process of hydraulic fracturing, the initial permeability, clay content, pore types, and pore connection should be given special attention.

\section{Conclusions}

Tight sand gas plays a very significant role in unconventional resources. Ordos basin is full of tight gas. However, there is severe aqueous phase damage during drilling, fracturing, and so on. Even though by flowback behavior, there 


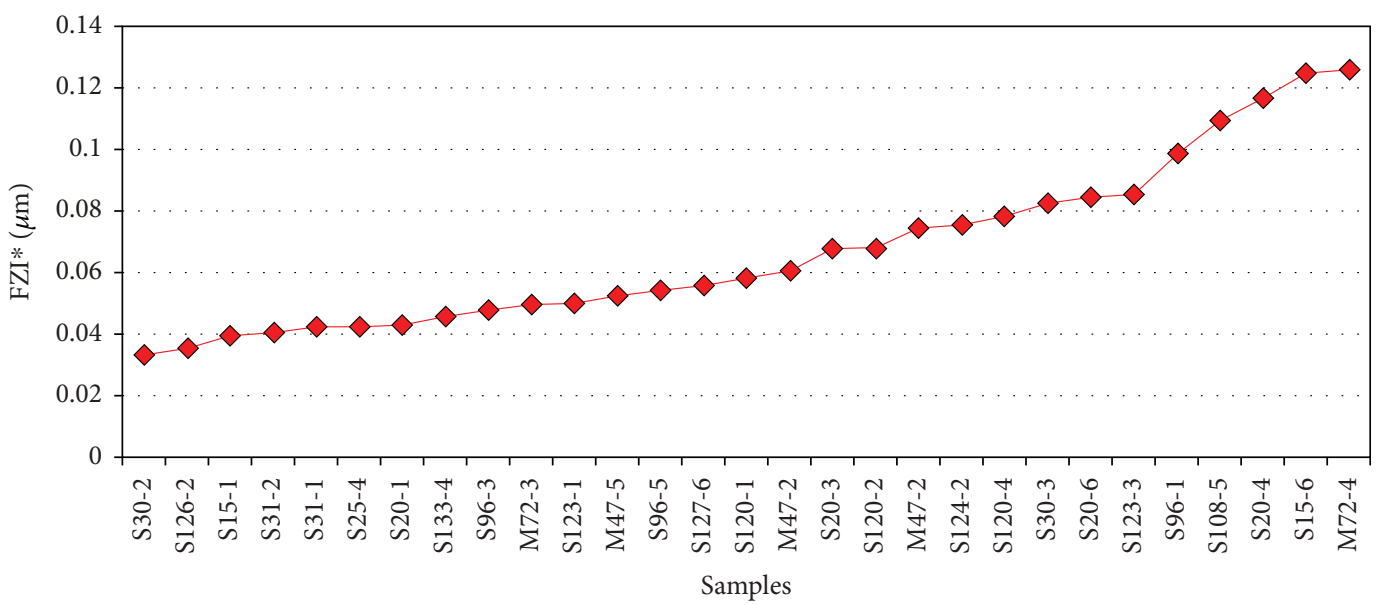

FIgURE 17: The FZI* of samples.

is still large amount of liquid retaining in the formation. In order to research this behavior, many experiments were carried out, including tight sand property and nitrogen displacement. The detailed conclusions were shown as follows.

(1) Taiyuan formation has big pores and strong compression among particles. There are lots of microcracks, which is prone to close during increasing stress. There are lots of small cracks in $\mathrm{H} 8$ formation. Usually, these cracks are too narrow, so that strong permeability stress sensitivity appears during loading process

(2) Tight sand has strong permeability stress sensitivity. In most cases, the permeability decreases greatly when confining pressure changes from $5 \mathrm{MPa}-$ $25 \mathrm{MPa}$. More than half of the permeability has been damaged. After the confining pressure reduced to the initial confining pressure $(5 \mathrm{MPa})$, there are still large amount of permeability being lost

(3) Tight sand has weak rock expansion characteristics, when it was compared with shale rock and volcanic rock. This characteristic own to its low clay content. The rock expansion rate is consistent with the clay content. The more clay is, the more severe the sample expansion rate is

(4) Through nitrogen displacement experiment, in most cases, the flowback rate and permeability recovery rate have negative relationship with clay content and positive relationship with initial permeability

Based on above research, clay expansion preventing additives should be added in the fracturing fluid to prevent clay expansion, reduce fluid retention into formation, and increase permeability recovery rate after flowback. When it comes to low permeability formation, preventing liquid filtration is a better choice, because not enough displacement pressure can be obtained. For relative high-permeability formation, quick flowback is a good choice to move liquid out of formation and increase permeability. Our research contributes to better understand the formation characteristics and its influence on the gas displacement to remove aqueous phase trapping.

\section{Data Availability}

The data used to support the findings of this study are included within the article.

\section{Conflicts of Interest}

The authors declare that they have no conflicts of interest.

\section{Acknowledgments}

This work was supported by the National Science and Technology Major Project (2017ZX05039-004, 2017ZX05069), the National Natural Science Foundation of China (Grant 51604287), the Science Foundation of China University of Petroleum, Beijing at Karamay (No. 00000), the National Natural Science Foundation Major Project (51490652), the National 973 Project (2015CB250903), and the "Typical project for development of large scale low permeability lithologic oil/gas reservoirs in Ordos basin" (2016ZX05050).

\section{References}

[1] S. A. Holditch, "Tight gas sands," Journal of Petroleum Technology, vol. 58, no. 6, pp. 86-93, 2006.

[2] H. Huang, W. Sun, F. Xiong et al., "A novel method to estimate subsurface shale gas capacities," Fuel, vol. 232, pp. 341350, 2018.

[3] W. Ji, Y. Song, Z. Jiang et al., "Estimation of marine shale methane adsorption capacity based on experimental investigations of Lower Silurian Longmaxi formation in the Upper Yangtze Platform, south China," Marine and Petroleum Geology, vol. 68, pp. 94-106, 2015.

[4] C. Li, Y. Shen, H. GE, S. SU, and Z. YANG, "Analysis of spontaneous imbibition in fractal tree-like network system," Fractals, vol. 24, no. 3, article 1650035, 2016. 
[5] C. Li, Y. Shen, H. Ge et al., "Analysis of capillary rise in asymmetric branch-like capillary," Fractals, vol. 24, no. 2, article 1650024, 2016.

[6] Q. Luo, N. Zhong, Y. Liu, Y. Qu, and L. Ma, "Organic geochemical characteristics and accumulation of the organic matter in the Jurassic to Cretaceous sediments of the Saihantala Sag, Erlian Basin, China," Marine and Petroleum Geology, vol. 92, pp. 855-867, 2018.

[7] Z. Rui, J. Lu, Z. Zhang et al., "A quantitative oil and gas reservoir evaluation system for development," Journal of Natural Gas Science and Engineering, vol. 42, pp. 31-39, 2017.

[8] Z. Rui, X. Wang, Z. Zhang et al., "A realistic and integrated model for evaluating oil sands development with steam assisted gravity drainage technology in Canada," Applied Energy, vol. 213, pp. 76-91, 2018.

[9] D. J. Soeder, "Porosity and permeability of eastern Devonian gas shale," SPE Formation Evaluation, vol. 3, no. 1, pp. 116124, 1988.

[10] W. K. Camp, "Pore-throat sizes in sandstones, tight sandstones, and shales: discussion," AAPG Bulletin, vol. 95, no. 8, pp. 1443-1447, 2011.

[11] H. Huang, L. Chen, W. Sun et al., "Pore-throat structure and fractal characteristics of Shihezi formation tight gas sandstone in the Ordos basin, China," Fractals, vol. 26, no. 2, article 1840005, 2018.

[12] P. H. Nelson, "Pore-throat sizes in sandstones, tight sandstones, and shales," AAPG Bulletin, vol. 93, no. 3, pp. 329$340,2009$.

[13] Y. Shen, H. Ge, M. Meng, Z. Jiang, and X. Yang, "Effect of water imbibition on shale permeability and its influence on gas production," Energy \& Fuels, vol. 31, no. 5, pp. 49734980, 2017.

[14] J. Zhao, W. Zhang, J. Li, Q. Cao, and Y. Fan, "Genesis of tight sand gas in the Ordos basin, China," Organic Geochemistry, vol. 74, pp. 76-84, 2014.

[15] J. A. Rushing, K. E. Newsham, and T. A. Blasingame, "Rock typing: keys to understanding productivity in tight gas sands," in SPE Unconventional Reservoirs Conference, p. 31, Keystone, Colorado, USA, February 2008.

[16] D. B. Silin, T. J. Kneafsey, J. B. Ajo-Franklin, and P. S. Nico, "A multimodal 3D imaging study of natural gas flow in tight sands," in SPE Annual Technical Conference and Exhibition, p. 33, Denver, Colorado, USA, October-November 2011.

[17] D. S. Ulmer-Scholle, P. A. Scholle, J. Schieber, and R. J. Raine, Sand \& Sandstone Textures, American Association of Petroleum Geologists, 2014.

[18] X. Wei, "Pore structure prediction for tight sandstone and verification with X-CT," in SEG Technical Program Expanded Abstracts 2016, p. 5, Dallas, Texas, September 2016.

[19] J. Cai, W. Wei, X. Hu, R. Liu, and J. Wang, "Fractal characterization of dynamic fracture network extension in porous media," Fractals, vol. 25, no. 2, article 1750023, 2017.

[20] H. Huang, W. Sun, W. Ji et al., "Effects of pore-throat structure on gas permeability in the tight sandstone reservoirs of the Upper Triassic Yanchang formation in the Western Ordos basin, China," Journal of Petroleum Science and Engineering, vol. 162, pp. 602-616, 2018.

[21] H. Kazemi, "Low-permeability gas sands," Journal of Petroleum Technology, vol. 34, no. 10, pp. 2229-2232, 1982.
[22] P. W. MacAvoy, "The natural gas policy act of 1978," Natural Resources Journal, vol. 19, no. 4, pp. 811-828, 1979.

[23] P. Randolph, D. Soeder, and P. Chowdiah, "Porosity and permeability of tight sands," in SPE Unconventional Gas Recovery Symposium, Pittsburgh, Pennsylvania, May 1984.

[24] Z. Rui, K. Cui, X. Wang et al., "A comprehensive investigation on performance of oil and gas development in Nigeria: technical and non-technical analyses," Energy, vol. 158, pp. 666-680, 2018.

[25] B. H. Adams, "Stress-sensitive permeability in a highpermeability sandstone reservoir-the Kuparuk field," in SPE California Regional Meeting, Ventura, California, March 1983.

[26] D. H. Gray and I. Fatt, "The effect of stress on permeability of sandstone cores," Society of Petroleum Engineers Journal, vol. 3, no. 2, pp. 95-100, 1963.

[27] N. H. Kilmer, N. R. Morrow, and J. K. Pitman, "Pressure sensitivity of low permeability sandstones," Journal of Petroleum Science and Engineering, vol. 1, no. 1, pp. 65-81, 1987.

[28] J. Vairogs, C. L. Hearn, D. W. Dareing, and V. W. Rhoades, "Effect of rock stress on gas production from lowpermeability reservoirs," Journal of Petroleum Technology, vol. 23, no. 9, pp. 1161-1167, 1971.

[29] W. F. Brace, J. B. Walsh, and W. T. Frangos, "Permeability of granite under high pressure," Journal of Geophysical Research, vol. 73, no. 6, pp. 2225-2236, 1968.

[30] X. Cui, A. M. M. Bustin, and R. M. Bustin, "Measurements of gas permeability and diffusivity of tight reservoir rocks: different approaches and their applications," Geofluids, vol. 9, no. 3, pp. 208-223, 2009.

[31] A. I. Dicker and R. M. Smits, "A practical approach for determining permeability from laboratory pressure-pulse decay measurements," in International Meeting on Petroleum Engineering, Tianjin, China, November 1988.

[32] D. L. Freeman and D. C. Bush, "Low-permeability laboratory measurements by nonsteady-state and conventional methods," Society of Petroleum Engineers Journal, vol. 23, no. 6, pp. 928936, 1983.

[33] S. C. Jones, "A technique for faster pulse-decay permeability measurements in tight rocks," SPE Formation Evaluation, vol. 12, no. 1, pp. 19-26, 1997.

[34] G. M. Narahara and K. R. Moore, "A new method for the measurement of gas relative permeability and water saturation simultaneously in low-permeability cores," in SPE Annual Technical Conference and Exhibition, Houston, Texas, October 1988.

[35] J. D. Walls, A. M. Nur, and T. Bourbie, "Effects of pressure and partial water saturation on gas permeability in tight sands: experimental results," Journal of Petroleum Technology, vol. 34, no. 4, pp. 930-936, 1982.

[36] R. Rezaee, A. Saeedi, and B. Clennell, "Tight gas sands permeability estimation from mercury injection capillary pressure and nuclear magnetic resonance data," Journal of Petroleum Science and Engineering, vol. 88-89, pp. 92-99, 2012.

[37] R. Brooks and A. Corey, "A simple correlation between permeabilities and mercury capillary pressures," Journal of Petroleum Technology, vol. 33, pp. 2498-2504, 1981.

[38] J. T. Comisky, K. Newsham, J. A. Rushing, and T. A. Blasingame, "A comparative study of capillary-pressurebased empirical models for estimating absolute permeability in tight gas sands," in SPE Annual Technical Conference 
and Exhibition, Anaheim, California, USA, November 2007.

[39] C. C. Huet, J. A. Rushing, K. E. Newsham, and T. A. Blasingame, "A modified purcell/burdine model for estimating absolute permeability from mercury-injection capillary pressure data," in International Petroleum Technology Conference, Doha, Qatar, November 2005.

[40] J. D. Wells and J. O. Amaefule, "Capillary pressure and permeability relationships in tight gas sands," in SPE/DOE Low Permeability Gas Reservoirs Symposium, Denver, Colorado, March 1985.

[41] J. Di and J. L. Jensen, "A new approach for permeability prediction with NMR measurements in tight formations," SPE Reservoir Evaluation and Engineering, vol. 19, no. 3, pp. 481-493, 2016.

[42] C. M. Prince, D. D. Steele, and C. A. Devier, "Permeability estimation in tight gas sands and shales using NMR-a new interpretive methodology," in 9th AAPG ICE meeting, Rio de Janero, Brazil, 2009.

[43] H. Parvizi, S. Rezaei-Gomari, F. Nabhani, A. Turner, and W. C. Feng, "Hydraulic fracturing performance evaluation in tight sand gas reservoirs with high perm streaks and natural fractures," in EUROPEC 2015, p. 19, Madrid, Spain, June 2015.

[44] M. P. Scott, T. Stephens, R. Durant, J. McGowen, W. Thom, and R. Woodroof, "Investigating hydraulic fracturing in tight gas sand and shale gas reservoirs in the Cooper Basin," in SPE Unconventional Resources Conference and ExhibitionAsia Pacific, p. 26, Brisbane, Australia, November 2013.

[45] Y. Shen, H. Ge, X. Zhang, L. Chang, D. Liu, and J. Liu, "Impact of fracturing liquid absorption on the production and waterblock unlocking for shale gas reservoir," Advances in GeoEnergy Research, vol. 2, no. 2, pp. 163-172, 2018.

[46] B. Wei, Q. Li, F. Jin, H. Li, and C. Wang, "The potential of a novel nanofluid in enhancing oil recovery," Energy \& Fuels, vol. 30, no. 4, pp. 2882-2891, 2016.

[47] Q. You, H. Wang, Y. Zhang, Y. Liu, J. Fang, and C. Dai, "Experimental study on spontaneous imbibition of recycled fracturing flow-back fluid to enhance oil recovery in low permeability sandstone reservoirs," Journal of Petroleum Science and Engineering, vol. 166, pp. 375-380, 2018.

[48] D. H. Le, H. N. Hoang, and J. Mahadevan, "Gas recovery from tight sands: impact of capillarity," SPE Journal, vol. 17, no. 4, pp. 981-991, 2012.

[49] D. B. Bennion and F. B. Thomas, "Formation damage issues impacting the productivity of low permeability, low initial water saturation gas producing formations," Journal of Energy Resources Technology, vol. 127, no. 3, pp. 240-247, 2005.

[50] D. B. Bennion, F. B. Thomas, R. F. Bietz, and D. W. Bennion, "Remediation of water and hydrocarbon phase trapping problems in low permeability gas reservoirs," Journal of Canadian Petroleum Technology, vol. 38, no. 8, 1999.

[51] Y. Kang, C. Xu, L. You, H. Yu, and B. Zhang, "Comprehensive evaluation of formation damage induced by working fluid loss in fractured tight gas reservoir," Journal of Natural Gas Science and Engineering, vol. 18, pp. 353-359, 2014.

[52] A. Mirzaei-Paiaman, K. Dalvand, I. Oraki Kohshour, M. Masihi, and J. Moghadasi, "A study on the key influential factors of a gas reservoir's potential for aqueous phase trapping," Energy Sources, Part A: Recovery, Utilization, and Environmental Effects, vol. 34, no. 16, pp. 1541-1549, 2012.
[53] A. Mirzaei-Paiaman, M. Masihi, and J. Moghadasi, "Formation damage through aqueous phase trapping: a review of the evaluating methods," Petroleum Science and Technology, vol. 29, no. 11, pp. 1187-1196, 2011.

[54] A. Mirzaei Paiaman, J. Moghadasi, and M. Masihi, "Formation damage through aqueous phase trapping in gas reservoirs," in SPE Deep Gas Conference and Exhibition, p. 8, Manama, Bahrain, January 2010.

[55] K. W. Shanley, R. M. Cluff, and J. W. Robinson, "Factors controlling prolific gas production from low-permeability sandstone reservoirs: implications for resource assessment, prospect development, and risk analysis," AAPG Bulletin, vol. 88, no. 8, pp. 1083-1121, 2004.

[56] S. A. Holditch, "Factors affecting water blocking and gas flow from hydraulically fractured gas wells," Journal of Petroleum Technology, vol. 31, no. 12, pp. 1515-1524, 1979.

[57] M. Meng, H. Ge, W. Ji, Y. Shen, and S. Su, "Monitor the process of shale spontaneous imbibition in co-current and counter-current displacing gas by using low field nuclear magnetic resonance method," Journal of Natural Gas Science and Engineering, vol. 27, pp. 336-345, 2015.

[58] M. Meng, H. Ge, W. Ji, X. Wang, and L. Chen, "Investigation on the variation of shale permeability with spontaneous imbibition time: sandstones and volcanic rocks as comparative study," Journal of Natural Gas Science and Engineering, vol. 27, pp. 1546-1554, 2015.

[59] A. Abrams and H. J. Vinegar, "Impairment mechanisms in Vicksburg tight gas sands," in SPE/DOE Low Permeability Gas Reservoirs Symposium, p. 12, Denver, Colorado, March 1985.

[60] S. E. Buckley and M. C. Leverett, "Mechanism of fluid displacement in sands," Transactions of the AIME, vol. 146, no. 1, pp. 107-116, 1942.

[61] J. Kamath and C. Laroche, "Laboratory-based evaluation of gas well deliverability loss caused by water blocking," SPE Journal, vol. 8, no. 1, pp. 71-80, 2003.

[62] J. Mahadevan and M. M. Sharma, "Factors affecting clean-up of water-blocks: a laboratory investigation," SPE Journal, vol. 10, no. 3, pp. 238-246, 2005.

[63] S. Motealleh and S. L. Bryant, "Quantitative mechanism for permeability reduction by small water saturation in tight-gas sandstones," SPE Journal, vol. 14, no. 2, pp. 252-258, 2009.

[64] S. Zhu, "Experiment research of tight sandstone gas reservoir stress sensitivity based on the capillary bundle mode," in SPE Annual Technical Conference and Exhibition, New Orleans, Louisiana, USA, September-October 2013.

[65] A. Mirzaei-Paiaman, M. Ostadhassan, R. Rezaee, H. SaboorianJooybari, and Z. Chen, "A new approach in petrophysical rock typing," Journal of Petroleum Science and Engineering, vol. 166, pp. 445-464, 2018.

[66] A. Mirzaei-Paiaman, H. Saboorian-Jooybari, and P. Pourafshary, "Improved method to identify hydraulic flow units for reservoir characterization," Energy Technology, vol. 3, no. 7, pp. 726-733, 2015. 

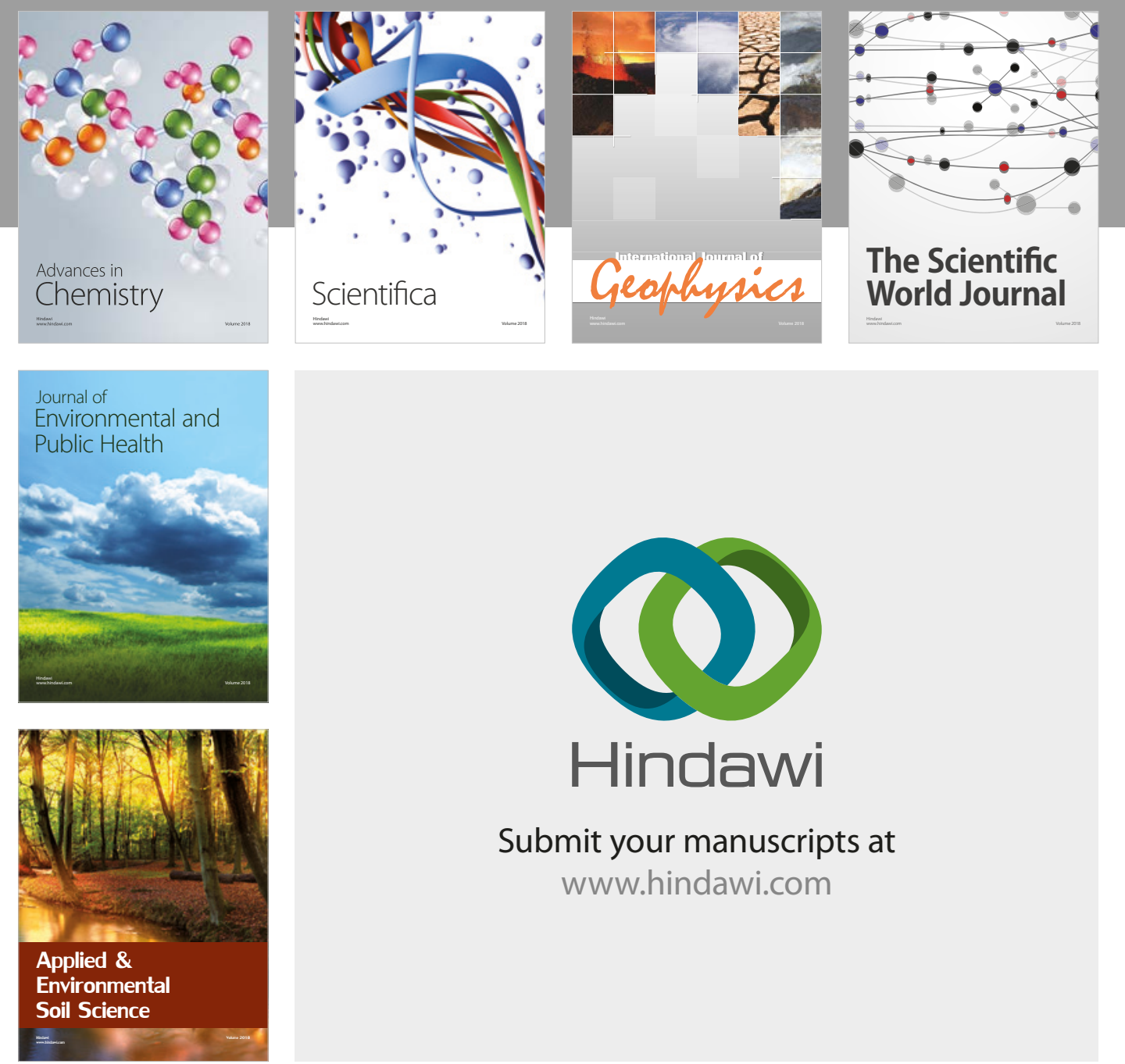

The Scientific

\section{World Journal}
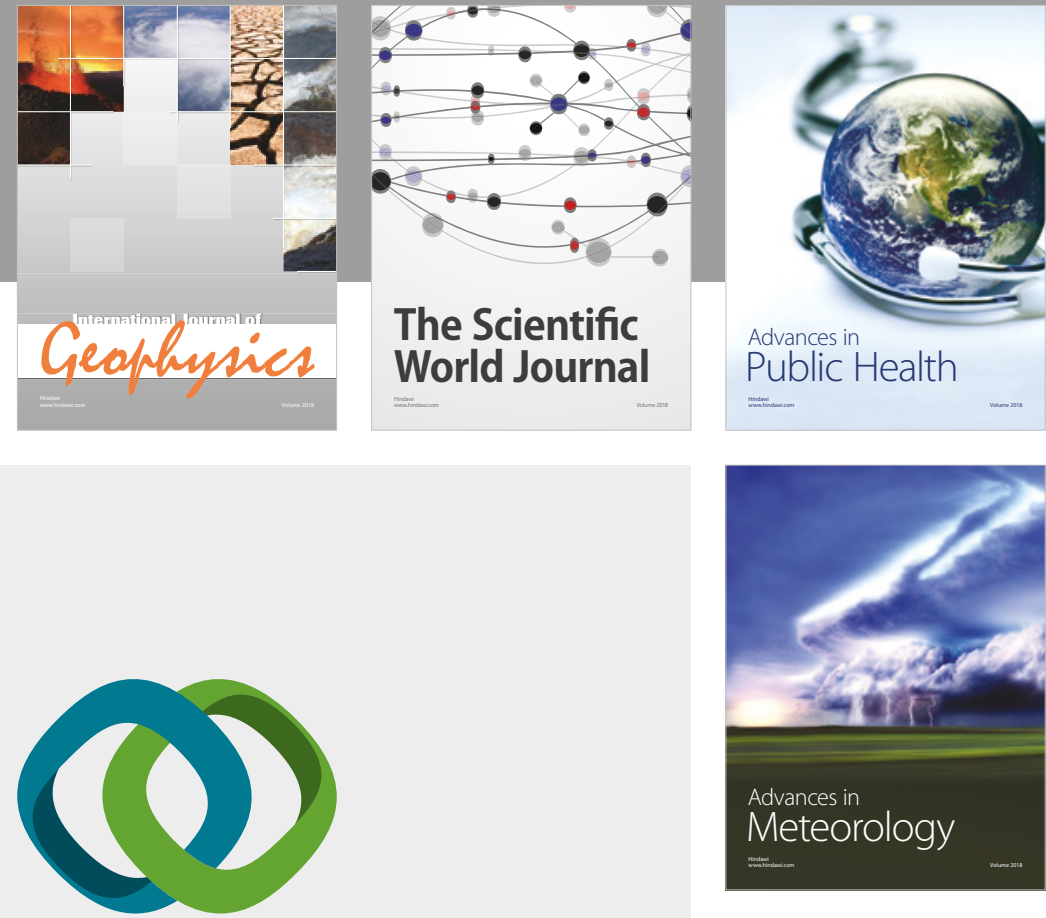

Advan

Public Health

\section{Hindawi}

Submit your manuscripts at

www.hindawi.com
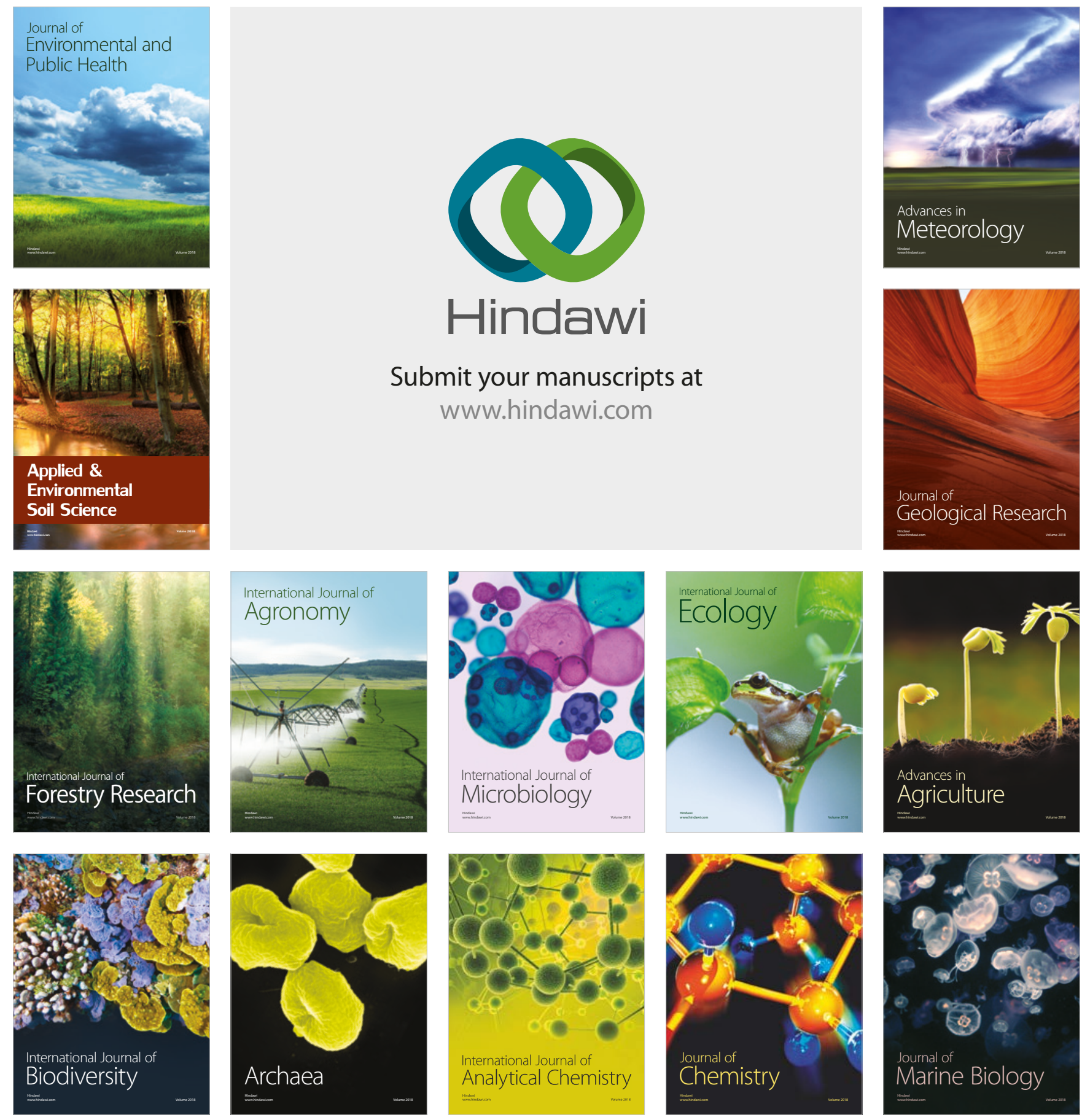